
\title{
28 Research Suare \\ The expression patterns and the prognostic roles of PTPN family members in digestive tract cancers
}

\section{Jing Chen}

The First Affiliated Hospital of China Medical University

\section{Xu Zhao}

Liaoning Vocational College of Medicine

\section{Yuan Yuan}

The First Affiliated Hospital of China Medical University

Jing-jing Jing ( $\nabla$ hellojjjing@163.com )

The First Affiliated Hospital of China Medical University https://orcid.org/0000-0002-9807-8089

\section{Primary research}

Keywords: PTPN family members, digestive tract cancers, expression, prognosis, clinical features

Posted Date: March 31st, 2020

DOl: https://doi.org/10.21203/rs.3.rs-19689/v1

License: (c) (i) This work is licensed under a Creative Commons Attribution 4.0 International License. Read Full License

Version of Record: A version of this preprint was published at Cancer Cell International on June 12th, 2020. See the published version at https://doi.org/10.1186/s12935-020-01315-7. 


\section{Abstract}

Background Non-receptor protein tyrosine phosphatases (PTPNs) are a set of enzymes involved in the tyrosyl phosphorylation. The present study intended to clarify the associations between the expression patterns of PTPN family members and the prognosis of digestive tract cancers.

Method Expression profiling of PTPN family genes in digestive tract cancers were analyzed through ONCOMINE and UALCAN. Gene ontology enrichment analysis was conducted using the DAVID database. The gene-gene interaction network was performed by GeneMANIA and the protein-protein interaction (PPI) network was built using STRING portal couple with Cytoscape. Data from The Cancer Genome Atlas (TCGA) were downloaded for validation and to explore the relationship of the PTPN expression with clinicopathological parameters and survival of digestive tract cancers.

Results Most PTPN family members were associated with digestive tract cancers according to Oncomine, Ualcan and TCGA data. For esophageal carcinoma (ESCA), expression of PTPN1, PTPN4 and PTPN12 were upregulated; expression of PTPN20 was associated with poor prognosis. For stomach adenocarcinoma (STAD), expression of PTPN2, PTPN12 and PTPN22 was upregulated in cancer tissue; pathological grade was significantly correlated with PTPN3, PTPN5, PTPN7, PTPN11, PTPN13, PTPN14, PTPN18 and PTPN23; PTPN20 expression was related with both TNM stage and N stage; PTPN22 was associated with T stage and pathological grade; decreased expression of PTPN5 and PTPN13 was associated with worse overall survival of STAD, while elevated PTPN6 expression indicated better prognosis. For colon adenocarcinoma (COAD), expression of PTPN1, PTPN11, PTPN12 and PTPN13 was upregulated, while expression of PTPN18, PTPN21 and PTPN22 was decreased; expression of PTPN5, PTPN12, and PTPN14 was correlated with TNM stage and N stage; high PTPN5 or PTPN7 expression were associated with increased hazards of death. For rectum adenocarcinoma (READ), expression of PTPN12 was upregulated while PTPN21 and PTPN22 were downregulated.

Conclusion Members of PTPN family were differently expressed in digestive tract cancers and matched normal tissues. Correlation were found between PTPN genes and clinicopathological parameters of patients. Expression of PTPN12 was upregulated in all of the ESCA, STAD, COAD and READ. PTPN5 was associated with the clinical features and prognosis of both STAD and COAD.

\section{Background}

Tyrosyl phosphorylation is a dynamic and reversible process which plays a pivotal part in many cellular signaling pathways(1). The dephosphorylation of tyrosine residues are catalyzed by a series of enzymes named protein tyrosine phosphatases (PTPs)(2). Encoded by 107 genes, PTPs are sorted into four major superfamily classes(3), and every single PTP was denominated an official gene name by The Human Genome Organization in Nomenclature Committee. According to the latter system, 17 non-receptor PTPs which belong to the biggest family class I, are designated PTPN, followed by a number(3). There is mounting evidence suggesting that the cross-talk of the PTPN gene family members is involved in 
extensive physiological processes, such as cell proliferation, survival, immune response, migration, and metabolism (3-6). Previously published study stated that PTPN family members play an essential part in numerous diseases. For example, the expression of PTPN6 with the loss of PSTAT3 expression could be chosen as a biomarker for the prognosis of peripheral-T cell lymphoma(7). One research published recently noted that a deficiency of PTPN2 could enhance anti-tumor immunity and the therapeutic efficacy of CAR T cells to solid cancers(8). PTPN22 plays an important part in regulating autophagy and NLR family pyrin domain containing 3 inflammasome activation(9). It is hopeful that PTPN genes have potential to be served as prognostic and diagnostic indicators(10), and even therapeutic targets.

As main malignancies of gastrointestinal tract, esophagus cancer (EC), gastric cancer (GC) and colorectal cancer (CRC) are responsible for a large portion of cancer-related deaths worldwide, of which the data are $5.3 \%, 8.2 \%$ and $9.0 \%$ respectively(11). All of the three digestive tract cancers are ranked in the top 10 for incidence rates of tumors and have poor prognosis(11). Although a couple of diagnostic biomarkers have been observed, robust biomarkers to predict clinical outcomes are still in urgent need(12). Former investigations reported that the expression pattern of individual PTPNs and its correlations with patients in various digestive tract neoplasms, but research to date has not yet observed the whole picture of the entire PTPN family, from the aspects of prognostic role and expression characteristics. Personalized therapies based upon the genetics of individual cancer will be prior to other treatments in the near future. This research therefore is intended to illuminate the prognostic value of different PTPN genes to support potential biomarkers and new individualized targets for patients. In the current study, we analyzed the expression status of different PTPN members and their clinical and prognostic values to comprehensively evaluate the role of PTPNs in various digestive tract cancers.

\section{Methods}

Oncomine Database Analysis for the expression patterns of PTPN family in digestive tract cancers

Oncomine database is a cancer microarray database (https://www.oncomine.org/) which shows the expression information of genes in cancer and normal samples(13). Oncomine provides both microarray information from 715 datasets and a set of online data-mining functions. The expression levels of individual PTPN family members in different types of cancer were obtained from the Oncomine database. Student's $t$ test was applied to calculate the $P$ value for expression differences of PTPN family genes between normal controls and cancer samples. The threshold parameters of $P$ value and fold change were demarcated as 0.05 and 2 respectively.

Ualcan Database Analysis For The Validation

Ualcan is a publicly available web-portal (http://ualcan.path.uab.edu) that offers online analysis of data from The Cancer Genome Atlas (TCGA)(14). In this study, we used it to analyze the relative expression of PTPN family genes in esophageal carcinoma (ESCA), stomach adenocarcinoma (STAD), colon adenocarcinoma (COAD), rectum adenocarcinoma (READ) and normal samples. The expression level of 
PTPN members was normalized as transcript per million reads, and a P value of no more than 0.01 conducted through Student's $t$ test was considered to be significant.

TCGA Data Analysis for the association between PTPN family and prognosis of digestive tract cancers.

The Cancer Genome Atlas (TCGA) is a cancer genomics database (https://cancergenome.nih.gov/) which contains genomic information of over 2000 primary neoplasms and matched normal samples $(15,16)$. In our study, case information of 115 ESCA, 347 STAD and 273 COAD were extracted for further analysis. The Pearson $\mathrm{X}^{2}$ test was performed to evaluate the relationship between different PTPN expression status and clinicopathological features. The effects of different PTPN expressions on overall survival were estimated through univariate and multivariate Cox proportional hazards models with or without adjustment for confounding factors. Variables including TNM stage, sex and age were further adjusted during the evaluation. The medical data obtained was managed by $\mathrm{R}$ language (Version 3.6.1). $\mathrm{P}$ value $<$ 0.05 was regarded as statistically significant.

GO and PPI Analysis for Function and Interaction of PTPN family

Enrichment analysis of Gene Ontology (GO) of PTPN genes was explored using the Database for Annotation, Visualization and Integrated Discovery (DAVID; v.6.8; https://david.ncifcrf.gov/home.jsp; accessed on November 20,2019)(17). The gene-gene interaction network was structured using the Gene Multiple Association Network Integration Algorithm (GeneMANIA; https://www.genemania.org/; accessed on November 21, 2019)(18) and the Search Tool for the Retrieval of Interacting Genes Database (STRING v.10.0; https://string-db.org/; accessed on November 23, 2019) was used to create a protein-protein interaction (PPI) network(19). The Cytoscape software was applied to visualize network diagrams for PPI analysis(20).

\section{Results}

PTPN Genes Expression Patterns in Digestive Tract Cancers.

Before expression profiling analysis, we refined the chromosome location of all PTPN gene family members through published literature review. The detailed information was summarized in Table 1 . 
Table 1

Basic characteristics of PTPN family genes

\begin{tabular}{|c|c|c|c|c|c|}
\hline $\begin{array}{l}\text { HGNC ID } \\
\text { (gene) }\end{array}$ & $\begin{array}{l}\text { Gene } \\
\text { ID }\end{array}$ & $\begin{array}{l}\text { Approved } \\
\text { symbol }\end{array}$ & Synonym(s) & Exon & $\begin{array}{l}\text { Chromosomal } \\
\text { location }\end{array}$ \\
\hline HGNC:9642 & 5770 & PTPN1 & PTP1B & 10 & 20q13.13 \\
\hline \multirow[t]{3}{*}{ HGNC:9650 } & \multirow[t]{3}{*}{5771} & \multirow[t]{3}{*}{ PTPN2 } & TCELLPTP & \multirow[t]{3}{*}{15} & \multirow[t]{3}{*}{ 18p11.21 } \\
\hline & & & TC-PTP & & \\
\hline & & & ТСРТP & & \\
\hline HGNC:9655 & 5774 & PTPN3 & PTPH1 & 33 & $9 q 31$ \\
\hline HGNC:9656 & 5775 & PTPN4 & PTPMEG & 29 & $2 q 14.2$ \\
\hline \multirow[t]{3}{*}{ HGNC:9657 } & \multirow[t]{3}{*}{84867} & \multirow[t]{3}{*}{ PTPN5 } & STEP & \multirow[t]{3}{*}{16} & \multirow[t]{3}{*}{ 11p15.1 } \\
\hline & & & PTPSTEP & & \\
\hline & & & STEP61 & & \\
\hline \multirow[t]{5}{*}{ HGNC:9658 } & \multirow[t]{5}{*}{5777} & \multirow[t]{5}{*}{ PTPN6 } & $\mathrm{HCP}$ & \multirow[t]{5}{*}{17} & \multirow[t]{5}{*}{$12 \mathrm{p} 13.31$} \\
\hline & & & $\mathrm{HCPH}$ & & \\
\hline & & & PTP-1C & & \\
\hline & & & SHP-1 & & \\
\hline & & & SHP1 & & \\
\hline \multirow[t]{2}{*}{ HGNC:9659 } & \multirow[t]{2}{*}{5778} & \multirow[t]{2}{*}{ PTPN7 } & HEPTP & \multirow[t]{2}{*}{12} & \multirow[t]{2}{*}{$1 \mathrm{q} 32.1$} \\
\hline & & & LC-PTP & & \\
\hline HGNC:9661 & 5780 & PTPN9 & MEG2 & 13 & 15q24.2 \\
\hline \multirow[t]{5}{*}{ HGNC:9644 } & \multirow[t]{5}{*}{5781} & \multirow[t]{5}{*}{ PTPN11 } & BPTP3 & \multirow[t]{5}{*}{16} & \multirow[t]{5}{*}{$12 q 24.13$} \\
\hline & & & SH-PTP2 & & \\
\hline & & & SHP-2 & & \\
\hline & & & PTP2C & & \\
\hline & & & SHP2 & & \\
\hline \multirow[t]{2}{*}{ HGNC:9645 } & \multirow[t]{2}{*}{5782} & \multirow[t]{2}{*}{ PTPN12 } & PTPG1 & \multirow[t]{2}{*}{19} & \multirow[t]{2}{*}{ 7q11.23 } \\
\hline & & & PTP-PEST & & \\
\hline HGNC:9646 & 5783 & PTPN13 & PTP1E & 48 & $4 q 21.3$ \\
\hline
\end{tabular}




\begin{tabular}{|c|c|c|c|c|c|}
\hline $\begin{array}{l}\text { HGNC ID } \\
\text { (gene) }\end{array}$ & $\begin{array}{l}\text { Gene } \\
\text { ID }\end{array}$ & $\begin{array}{l}\text { Approved } \\
\text { symbol }\end{array}$ & Synonym(s) & Exon & $\begin{array}{l}\text { Chromosomal } \\
\text { location }\end{array}$ \\
\hline & & & PTP-BAS & & \\
\hline & & & PTPL1 & & \\
\hline & & & PTP-BL & & \\
\hline HGNC:9647 & 5784 & PTPN14 & PEZ & 21 & 1q32.3-q41 \\
\hline HGNC:9649 & 26469 & PTPN18 & BDP1 & 15 & $2 q 21.1$ \\
\hline \multirow[t]{4}{*}{ HGNC:23423 } & \multirow[t]{4}{*}{26095} & \multirow[t]{4}{*}{ PTPN20 } & bA42B19.1 & \multirow[t]{4}{*}{18} & \multirow[t]{4}{*}{$10 q 11.22$} \\
\hline & & & DKFZP566K0524 & & \\
\hline & & & bA142I17.1 & & \\
\hline & & & CT126 & & \\
\hline \multirow[t]{2}{*}{ HGNC:9651 } & \multirow[t]{2}{*}{11099} & \multirow[t]{2}{*}{ PTPN21 } & PTPD1 & \multirow[t]{2}{*}{23} & \multirow[t]{2}{*}{$14 q 31$} \\
\hline & & & PTPRL10 & & \\
\hline \multirow[t]{3}{*}{ HGNC:9652 } & \multirow[t]{3}{*}{26191} & \multirow[t]{3}{*}{ PTPN22 } & Lyp & \multirow[t]{3}{*}{24} & \multirow[t]{3}{*}{$1 \mathrm{p} 13.2$} \\
\hline & & & Lyp1 & & \\
\hline & & & Lyp2 & & \\
\hline \multirow[t]{3}{*}{ HGNC:14406 } & \multirow[t]{3}{*}{25930} & \multirow[t]{3}{*}{ PTPN23 } & DKFZP564F0923 & \multirow[t]{3}{*}{25} & \multirow[t]{3}{*}{$3 p 21.31$} \\
\hline & & & KIAA1471 & & \\
\hline & & & HD-PTP & & \\
\hline
\end{tabular}

All of these seventeen PTPN family members have been analyzed in our study. According to the analysis results of ONCOMINE, the expression of PTPN genes were different in all types of cancer and its matched normal tissues (Fig. 1). For EC samples, PTPN1, PTPN4, PTPN12, PTPN18 and PTPN21 were overexpressed, while PTPN3, PTPN11, PTPN13 and PTPN21 were downregulated. In GC tissues, the expression of PTPN5 and PTPN13 was decreased while at the same time PTPN2, PTPN12 and PTPN22 were highly expressed in patients. As for CRC patients, the expression of PTPN1, PTPN3, PTPN7, PTPN11, PTPN12, PTPN13 and PTPN14 was upregulated in patients with CRC, while PTPN2, PTPN18, PTPN20, PTPN21 and PTPN22 were expressed in a lower level in tissues. Comprehensively, the expression of PTPN12 was higher in EC, GC and CRC samples.

UALCAN was used to further verify the expression of PTPNs among ESCA, STAD, COAD, READ and their matched normal tissues in the TCGA datasets. As shown in the results of UALCAN (Fig. 2-5), there was a clear trend that the expression levels of PTPN1, PTPN2, PTPN4, PTPN6, PTPN7, PTPN9, PTPN12, 
PTPN22 and PTPN23 were statistically higher in samples of ESCA than in normal tissues; in STAD, PTPN1, PTPN2, PTPN3, PTPN4, PTPN6, PTPN7, PTPN9, PTPN11, PTPN12, PTPN18, PTPN22, and PTPN23 were significantly increased compared to normal samples; in COAD, PTPN1, PTPN2, PTPN4, PTPN11, PTPN12, PTPN13, and PTPN23 were overexpressed compared with normal samples, while PTPN9, PTPN18, PTPN21 and PTPN22 were lower than normal tissues; in READ, the expression levels of PTPN4, PTPN12, and PTPN23 were higher than normal samples while PTPN21 and PTPN22 were decreased in patients compared to normal groups. Taken together, the results above indicated that the expression status of PTPN4, PTPN12 and PTPN23 were upregulated in ESCA, STAD, COAD and READ. PTPN21 and PTPN22 were upregulated in ESCA and STAD but downregulated in COAD.

Correlations between PTPN Members and Clinicopathological Parameters.

Association of PTPN family genes expression status with different clinicopathological features of ESCA, STAD and COAD were analyzed in the study. For ESCA, no statistically association was found between PTPN members and clinicopathological parameters (Additional file 1: Table S1). For STAD, grade was significantly correlated with PTPN3, PTPN11, PTPN13, PTPN14, and PTPN18 ( $p=0.015,0.021,0.005$, 0.002 and 0.034, resp.) (Additional file 1: Table S2). In addition, PTPN5, PTPN7 and PTPN23 showed statistically association with pathological grade of STAD with a $p$ value of no more than 0.001. Besides, PTPN20 expression was related with TNM stage $(p=0.002)$ and $N$ stage $(p=0.038)$; PTPN22 was significantly related with grade $(p<0.001)$ and T stage $(p=0.039)$ (Additional file 1: Table S2). For COAD, TNM stage was correlated with expression of PTPN5, PTPN12, and PTPN14 ( $p=0.049,0.027,0.002$, resp.; Additional file 1: Table S3); N stage was associated with expression of PTPN5, PTPN12, and PTPN14 ( $p=0.034,0.018$ and 0.004, resp.; Additional file 1: Table S3). According to the results above, PTPN5 and PTPN14 were associated with the clinicopathological parameters of both STAD and COAD.

Prognostic Roles of PTPN Family Genes.

The analysis results of the relationship between PTPN family genes and the prognosis of digestive tract cancers showed that for ESCA, elevated expression of PTPN20 was associated with a worse overall survival (OS) of ESCA in multivariate model $(\mathrm{p}=0.038$, adjusted $\mathrm{HR}=1.982,95 \% \mathrm{Cl}=1.039-3.780$; Table 2). 
Table 2

Prognostic role of PTPN family genes in ESCA

\begin{tabular}{|lllll|}
\hline GENE & Univariate analysis & & Multivariate analysis & \\
\cline { 2 - 5 } & HR (95\%Cl) & $\mathbf{P}$ & Adjusted HR (95\%Cl) & $\mathbf{P}$ \\
\hline PTPN1 & $0.831(0.427-1.615)$ & 0.585 & $0.724(0.367-1.427)$ & 0.350 \\
\hline PTPN2 & $1.171(0.601-2.285)$ & 0.643 & $1.075(0.546-2.119)$ & 0.834 \\
\hline PTPN3 & $1.020(0.514-2.026)$ & 0.954 & $0.776(0.383-1.571)$ & 0.481 \\
\hline PTPN4 & $0.617(0.304-1.253)$ & 0.182 & $0.758(0.348-1.648)$ & 0.484 \\
\hline PTPN5 & $0.982(0.494-1.952)$ & 0.958 & $0.935(0.452-1.933)$ & 0.855 \\
\hline PTPN6 & $1.123(0.565-2.230)$ & 0.741 & $1.398(0.678-2.886)$ & 0.364 \\
\hline PTPN7 & $0.839(0.432-1.630)$ & 0.605 & $0.817(0.394-1.693)$ & 0.586 \\
\hline PTPN9 & $1.499(0.774-2.904)$ & 0.230 & $1.302(0.666-2.546)$ & 0.440 \\
\hline PTPN11 & $0.632(0.293-1.362)$ & 0.241 & $0.597(0.275-1.294)$ & 0.191 \\
\hline PTPN12 & $0.706(0.356-1.399)$ & 0.319 & $0.518(0.254-1.057)$ & 0.071 \\
\hline PTPN13 & $0.695(0.332-1.453)$ & 0.334 & $1.009(0.455-2.234)$ & 0.983 \\
\hline PTPN14 & $1.116(0.558-2.235)$ & 0.756 & $1.439(0.687-3.016)$ & 0.335 \\
\hline PTPN18 & $0.875(0.453-1.693)$ & 0.692 & $1.001(0.494-2.031)$ & 0.997 \\
\hline PTPN20 & $1.697(0.901-3.194)$ & 0.101 & $1.982(1.039-3.780)$ & 0.038 \\
\hline PTPN21 & $0.627(0.279-1.409)$ & 0.259 & $0.580(0.244-1.381)$ & 0.219 \\
\hline PTPN22 & $0.911(0.469-1.772)$ & 0.784 & $0.576(0.264-1.255)$ & 0.165 \\
\hline PTPN23 & $0.664(0.318-1.387)$ & 0.276 & $0.487(0.228-1.040)$ & 0.063 \\
\hline
\end{tabular}

For STAD, decreased PTPN5 expression was associated with worse OS according to univariate analysis $(p=0.006, H R=1.680,95 \% \mathrm{Cl}=1.162-2.429)$ and multivariate analysis $(p=0.004$, adjusted $H R=1.753$, $95 \% \mathrm{Cl}=1.192-2.577$ ), while elevated expression of PTPN6 indicated longer OS based on the results of univariate analysis $(p=0.028, \mathrm{HR}=0.633,95 \% \mathrm{Cl}=0.421-0.951)$ and multivariate analysis $(\mathrm{p}=0.017$, adjusted $\mathrm{HR}=0.606,95 \% \mathrm{Cl}=0.402-0.915)$ (Table 3$)$. Besides, univariate analysis exhibited that there was a significant association between decreased PTPN13 expression and decreased OS $(p=0.036, H R=$ $1.471,95 \% \mathrm{Cl}=1.026-2.109)$. 
Table 3

Prognostic role of PTPN family genes in STAD

\begin{tabular}{|lllll|}
\hline GENE & Univariate analysis & & Multivariate analysis & \\
\cline { 2 - 5 } & HR (95\%Cl) & $\mathbf{P}$ & Adjusted HR (95\%Cl) & $\mathbf{P}$ \\
\hline PTPN1 & $1.238(0.857-1.788)$ & 0.255 & $1.118(0.772-1.619)$ & 0.553 \\
\hline PTPN2 & $1.174(0.806-1.710)$ & 0.405 & $1.219(0.836-1.779)$ & 0.304 \\
\hline PTPN3 & $0.879(0.592-1.306)$ & 0.524 & $0.844(0.563-1.266)$ & 0.412 \\
\hline PTPN4 & $0.854(0.580-1.258)$ & 0.424 & $0.802(0.543-1.183)$ & 0.265 \\
\hline PTPN5 & $1.680(1.162-2.429)$ & 0.006 & $1.753(1.192-2.577)$ & 0.004 \\
\hline PTPN6 & $0.633(0.421-0.951)$ & 0.028 & $0.606(0.402-0.915)$ & 0.017 \\
\hline PTPN7 & $1.065(0.731-1.551)$ & 0.743 & $0.956(0.650-1.405)$ & 0.819 \\
\hline PTPN9 & $1.229(0.853-1.769)$ & 0.269 & $1.233(0.855-1.778)$ & 0.263 \\
\hline PTPN11 & $1.373(0.951-1.984)$ & 0.091 & $1.389(0.957-2.018)$ & 0.084 \\
\hline PTPN12 & $1.202(0.811-1.779)$ & 0.359 & $1.152(0.778-1.707)$ & 0.479 \\
\hline PTPN13 & $1.471(1.026-2.109)$ & 0.036 & $1.431(0.995-2.058)$ & 0.054 \\
\hline PTPN14 & $1.341(0.927-1.937)$ & 0.118 & $1.350(0.924-1.973)$ & 0.121 \\
\hline PTPN18 & $1.158(0.787-1.705)$ & 0.456 & $1.213(0.819-1.796)$ & 0.334 \\
\hline PTPN20 & $1.185(0.813-1.727)$ & 0.377 & $1.389(0.946-2.040)$ & 0.094 \\
\hline PTPN21 & $1.237(0.852-1.797)$ & 0.264 & $1.258(0.862-1.836)$ & 0.234 \\
\hline PTPN22 & $0.913(0.614-1.358)$ & 0.654 & $0.844(0.561-1.271)$ & 0.418 \\
\hline PTPN23 & $0.954(0.655-1.390)$ & 0.806 & $0.998(0.681-1.463)$ & 0.992 \\
\hline
\end{tabular}

COAD patients with high PTPN5 expression showed increased hazards of death in univariate model $(\mathrm{p}=$ $0.021, \mathrm{HR}=1.947,95 \% \mathrm{Cl}=1.105-3.431$; Table 4). Elevated expression of PTPN7 was significantly associated with the unfavorable OS for every COAD patients according to multivariate analysis $(p=0.013$, adjusted $\mathrm{HR}=2.043,95 \% \mathrm{Cl}=1.164-3.584 ;$ Table 4). 
Table 4

Prognostic role of PTPN family genes in COAD

\begin{tabular}{|lllll|}
\hline \multirow{2}{*}{ GENE } & Univariate analysis & \multicolumn{3}{c|}{ Multivariate analysis } \\
\cline { 2 - 5 } & HR (95\%Cl) & P & Adjusted HR (95\%Cl) & P \\
\hline PTPN1 & $1.492(0.863-2.579)$ & 0.152 & $1.476(0.841-2.588)$ & 0.175 \\
\hline PTPN2 & $1.136(0.653-1.975)$ & 0.652 & $1.009(0.571-1.783)$ & 0.976 \\
\hline PTPN3 & $1.022(0.576-1.814)$ & 0.941 & $0.912(0.505-1.649)$ & 0.761 \\
\hline PTPN4 & $1.003(0.565-1.780)$ & 0.993 & $0.903(0.507-1.609)$ & 0.729 \\
\hline PTPN5 & $1.947(1.105-3.431)$ & 0.021 & $1.681(0.945-2.991)$ & 0.077 \\
\hline PTPN6 & $0.825(0.859-2.553)$ & 0.158 & $1.328(0.764-2.306)$ & 0.314 \\
\hline PTPN7 & $1.700(0.984-2.940)$ & 0.057 & $2.043(1.164-3.584)$ & 0.013 \\
\hline PTPN9 & $0.825(0.428-1.593)$ & 0.567 & $0.821(0.424-1.589)$ & 0.558 \\
\hline PTPN11 & $1.525(0.698-2.266)$ & 0.446 & $1.618(0.885-2.959)$ & 0.118 \\
\hline PTPN12 & $1.525(0.885-2.629)$ & 0.129 & $0.962(0.539-1.718)$ & 0.896 \\
\hline PTPN13 & $1.186(0.661-2.130)$ & 0.568 & $1.105(0.607-2.010)$ & 0.744 \\
\hline PTPN14 & $1.706(0.978-2.977)$ & 0.060 & $1.142(0.646-2.018)$ & 0.648 \\
\hline PTPN18 & $1.500(0.852-2.640)$ & 0.160 & $1.503(0.835-2.706)$ & 0.174 \\
\hline PTPN20 & $1.218(0.699-2.125)$ & 0.487 & $1.499(0.853-2.636)$ & 0.160 \\
\hline PTPN21 & $0.853(0.443-1.643)$ & 0.634 & $0.808(0.418-1.564)$ & 0.528 \\
\hline PTPN22 & $1.622(0.945-2.782)$ & 0.079 & $1.637(0.949-2.825)$ & 0.076 \\
\hline PTPN23 & $0.893(0.483-1.652)$ & 0.719 & $0.519(0.268-1.002)$ & 0.051 \\
\hline
\end{tabular}

From the results above we can see that the expression of PTPN5 was associated with the prognosis of both STAD and COAD.

Function and Interaction of PTPN Family Genes.

GO analysis was basically grouped into three terms including molecular function groups, cellular component groups and biological process groups. The top 5 enriched categories obtained from the analysis results of each group were showed in Fig. 6a. GO analysis revealed that PTPN proteins were mainly related to cytoplasmic side of plasma membrane. PTPN genes exert their functions primarily on peptidyl-tyrosine dephosphorylation and protein tyrosine phosphatase activity. Further, the interaction analysis of PTPN genes at the gene level was performed by GeneMANIA to clarify the correlations among 
colocalization, shared protein domains, co-expression, prediction and pathways (Fig. 6b). As the proteinprotein interaction network of STRING analysis result revealed, interrelationships among PTPN gene family members were intricate (Fig. 6c).

\section{Discussion}

Being significant members of protein tyrosine phosphatases, PTPN regulates tyrosine phosphorylation and dephosphorylation in cellular signal transduction together with protein-tyrosine kinases(4). There are abundant investigations focusing on the links between individual PTPN family members and diverse neoplasms. However, no report has offered an overview of how PTPN family genes tie up with diverse gastrointestinal tumors up to now. This research for the first time investigated the expression patterns of PTPN genes, and illustrated the association between PTPN family genes and digestive tract cancers, which provide deeper insights into the clinical values of all the PTPN genes in various digestive tract cancers.

To explore the PTPN genes expression patterns in digestive tract cancers, we used two online database: Oncomine and Ualcan. As revealed by our study, expression levels of PTPN5 and PTPN13 were decreased, but PTPN2, PTPN12, and PTPN22 were overexpressed in human STAD compared with matched normal samples. Particularly, PTPN2, PTPN12 and PTPN22 were further verified in Ualcan. PTPN2 antagonizes cytokine signaling needed for T cell differentiation, homeostasis, and function by regulating the dephosphorylation and inactivation of Janus-activated kinase (JAK)- 1 and JAK-3, and their target substrates signal transducer and activator of transcription (STAT)-1, STAT-3 and STAT-5 in a cell context-dependent manner(21-24). Recent researches demonstrated that PTPN2 deletion can enhance the effectiveness of anti-tumor immunity $(8,25,26)$. Thus, PTPN2 expression is likely to possess potential medical significance in STAD and could be exploited as an attractive immunotherapy target. For CRC patients, PTPN3, PTPN7, PTPN11, PTPN12, PTPN13 and PTPN14 were upregulated while PTPN2, PTPN18, PTPN21, and PTPN22 expressions were decreased according to Oncomine. PTPN12, PTPN21, and PTPN22 were also further verified in Ualcan. PTPN3 was demonstrated to be served as a tumor suppressor gene in CRC(27). Another study illustrated that elevated PTPN3 expression promotes tumor recurrence and is detrimental to the prognosis of intrahepatic cholangiocarcinoma patients(28). Consistent with our results, Slattery ML et al(29) reported that PTPN11 expression is upregulated in CRC. PTPN11 was also suggested to impact the tumorigenesis and metastasis of CRC(30) and termed as a potential prognostic marker(31). The data in one report showed that in patients with gastric B-cell nonHodgkin's lymphoma, PTPN21 is over expressed(32). In ESCA, the expression levels of PTPN1, PTPN4, and PTPN12 were increased. PTPN12 expression was upregulated in both ESCA, STAD, COAD and READ. Recently PTPN12 is characterized as a tumor suppressor which antagonizes EGFR/HER2 signaling(33, 34). In hepatocellular carcinoma cells, PTPN12 regulates epithelial-mesenchymal transition which contributes to chemoresistance and metastasis(35). All of these indicate that many PTPNs function in the progress of cancer, and particularly, PTPN12 may play a crucial role for its increased levels in all of the three types of digestive tract cancers. 
There may also exist associations between differentially expressed PTPNs and prognosis of digestive tract cancers. To further figure out the associations, we then analyzed the interrelationships between PTPN expressions and the clinical outcomes of digestive tract cancers. As revealed by the current study, PTPN5, PTPN13 and PTPN22 were also associated with clinicopathological parameters of STAD. And decreased expression of PTPN5 and PTPN13 indicated worse OS of STAD patients, while high PTPN6 expression was associated with a favorable STAD OS. It is worth noting that SHP-1 protein encoded by PTPN6 mediates the tumor-suppressive function of TMEFF2 in STAD (36), which indicates expression of PTPN6 might influence the carcinogenesis of STAD patients. PTPN13 has been reported to regulate the resistance of human lung fibroblasts to Fas-induced apoptosis in previous study(37). Mutated PTPN13 was suggested to be a tumor suppressor gene in colorectal cancer(27). PTPN22 gene encodes an enzyme called lymphoid-specific tyrosine phosphatase, which functions as a master regulator in the biological process of relevant immune responses(38). Upregulation of PTPN22 could result in impairment of regulatory T-cell differentiation in patients with non-ST-segment elevation acute coronary syndromes(39). As for COAD, expression levels of PTPN5, PTPN12, and PTPN14 were correlated with clinicopathological parameters. Besides, elevation of PTPN5 and PTPN7 was significantly associated with increased death hazards of COAD patients respectively. PTPN5 could regulate tyrosine dephosphorylation needed for the activation of BAK, a noteworthy cell-death mediator in apoptosis(40). One study presents PTPN12 as a novel candidate that contributes to the heterogeneous susceptibility to colorectal cancer(41). It was once reported that PTPN14 regulated phosphorylation of p130Cas Y128 plays a crucial role in colorectal carcinogenesis(42). And mutated PTPN14 is suggested to be a tumor suppressor gene for colorectal cancer, regulating cellular pathways that are appropriate for therapeutic intervention(27). As for ESCA, our analysis indicated that only PTPN20 expression was related with a worse OS of patients. However, former research indicated that PTPN12 may serve as a potential prognostic indicator for esophagus cancer patients(43). Altogether, our results revealed that PTPN5 expression status was significantly related to clinical features and prognosis of both STAD and COAD, which warrants further investigation for its function in progress of digestive tract cancers.

In this study, GO analysis revealed that PTPN proteins were mainly related to cytoplasmic side of plasma membrane. PTPN genes exert their functions primarily on peptidyl-tyrosine dephosphorylation and protein tyrosine phosphatase activity, which was illustrated by dozens of publications. Substrate-trapping and biochemical analyses demonstrated that PTPN22 mainly dephosphorylates the tyrosine residues of SFKs and SFK substrates including the E3ubiquitin ligase c-Cbl57-59 and the T cell signaling protein Zap70(44-46). Our study revealed that the expression of many PTPN members were abnormal in digestive tract cancers. Not surprisingly, these abnormal expressed PTPN genes can screw up protein tyrosine phosphorylation levels and thus connected with the etiology of digestive tract cancers. In addition, the results of interaction network analysis at gene and protein levels further indicated that PTPN members and other genes comprehensively interact with each other. One experiment suggested that both PTPN1 and PTPN2 target protein mediator of IRF3 activation for dephosphorylation at Y245(47). PTPN2 and PTPN22 were demonstrated negatively regulating $T$ cell receptor signaling by dephosphorylating lymphocyte-specific protein tyrosine kinase $(44,48)$. Multiple efforts demonstrated that through binding 
and inactivating the mitogen activated protein kinase Erk2 and p38, PTPN5 and PTPN7 could negatively regulate cell proliferation as well as differentiation(49-52). Promoter hypermethylation of PTPN6 and PTPN13 was reported to inhibit the progression of diffuse large B cell lymphomas(53). In our study, PTPN5 and PTPN7 were found to be correlated with prognosis of colon adenocarcinoma patients, while PTPN6 and PTPN13 were statistically associated with the prognosis of STAD. All of these implied that there may exist alliance mechanisms in biological process of PTPN members and even in the progress of digestive tract cancers.

\section{Conclusions}

In summary, findings of our study illustrated the expression status and prognostic values of PTPN members in digestive tract cancers. The results indicated that several PTPN members were differentially expressed and related to clinical outcomes of patients with digestive tract cancers. Especially, level of PTPN12 expression was upregulated in both ESCA,STAD, COAD and READ. PTPN5 was associated with the clinical features and prognosis of both STAD and COAD. Future well-designed investigations are in required to elucidate the significance of our findings and thus develop the clinical utility of PTPNs.

\section{Abbreviations}

PTPs: Protein tyrosine phosphatases; PTPN: Non-receptor protein tyrosine phosphatase; EC: Esophagus cancer; GC: Gastric cancer; CRC: Colorectal cancer; TCGA: The Cancer Genome Atlas; ESCA: Esophageal carcinoma; STAD: Stomach adenocarcinoma; COAD: Colon adenocarcinoma; READ: Rectum adenocarcinoma; GO: Gene Ontology; DAVID: Database for Annotation, Visualization and Integrated Discovery; GeneMANIA: Gene Multiple Association Network Integration Algorithm; STRING: Search Tool for the Retrieval of Interacting Genes Database; PPI: Protein-protein interaction; OS: Overall survival; JAK: Janus-activated kinase; STAT: Signal transducer and activator of transcription.

\section{Declarations}

\section{Ethics approval and consent to participate}

Not applicable.

\section{Consent for publication}

Not applicable.

\section{Availability of data and materials}

The datasets analysed during the current study are available in the TCGA repository (https://cancergenome.nih.gov/).

\section{Competing interests}


The authors declare that they have no competing intersts in this work.

\section{Funding}

This work was supported by the National Natural Science Foundation of China (31800124).

\section{Authors' contributions}

$\mathrm{JC}$ collected the data and wrote the paper; JC, JJ and XZ performed the statistical analysis; JJ and YY conceived the study and revised the manuscript.All authors read and approved the final manuscript.

\section{Acknowledgements}

Not applicable.

\section{References}

1. Li X, Wilmanns M, Thornton J, Kohn M. Elucidating human phosphatase-substrate networks. Science signaling. 2013;6(275):rs10.

2. Hunter T. Tyrosine phosphorylation: thirty years and counting. Current opinion in cell biology. 2009;21(2):140-6.

3. Alonso A, Sasin J, Bottini N, Friedberg I, Friedberg I, Osterman A, et al. Protein tyrosine phosphatases in the human genome. Cell. 2004;117(6):699-711.

4. Tonks NK. Protein tyrosine phosphatases: from genes, to function, to disease. Nature reviews Molecular cell biology. 2006;7(11):833-46.

5. Julien SG, Dube N, Hardy S, Tremblay ML. Inside the human cancer tyrosine phosphatome. Nature reviews Cancer. 2011;11(1):35-49.

6. Yu ZH, Zhang ZY. Regulatory Mechanisms and Novel Therapeutic Targeting Strategies for Protein Tyrosine Phosphatases. Chemical reviews. 2018;118(3):1069-91.

7. Han JJ, O'Byrne M, Stenson MJ, Maurer MJ, Wellik LE, Feldman AL, et al. Prognostic and therapeutic significance of phosphorylated STAT3 and protein tyrosine phosphatase-6 in peripheral-T cell lymphoma. Blood cancer journal. 2018;8(11):110.

8. Wiede F, Lu KH, Du X, Liang S, Hochheiser K, Dodd GT, et al. PTPN2 phosphatase deletion in T cells promotes anti-tumour immunity and CAR T-cell efficacy in solid tumours. The EMBO journal. 2019:e103637.

9. Spalinger MR, Lang S, Gottier C, Dai X, Rawlings DJ, Chan AC, et al. PTPN22 regulates NLRP3mediated IL1B secretion in an autophagy-dependent manner. Autophagy. 2017;13(9):1590-601.

10. Zhang ZY. Drugging the Undruggable: Therapeutic Potential of Targeting Protein Tyrosine Phosphatases. Accounts of chemical research. 2017;50(1):122-9. 
11. Bray F, Ferlay J, Soerjomataram I, Siegel RL, Torre LA, Jemal A. Global cancer statistics 2018: GLOBOCAN estimates of incidence and mortality worldwide for 36 cancers in 185 countries. CA Cancer J Clin. 2018;68(6):394-424.

12. Taniguchi $H$, Moriya $C$, Igarashi $H$, Saitoh $A$, Yamamoto $H$, Adachi $Y$, et al. Cancer stem cells in human gastrointestinal cancer. Cancer Sci. 2016;107(11):1556-62.

13. Rhodes DR, Yu J, Shanker K, Deshpande N, Varambally R, Ghosh D, et al. ONCOMINE: a cancer microarray database and integrated data-mining platform. Neoplasia (New York, NY). 2004;6(1):1-6.

14. Chandrashekar DS, Bashel B, Balasubramanya SAH, Creighton CJ, Ponce-Rodriguez I, Chakravarthi B, et al. UALCAN: A Portal for Facilitating Tumor Subgroup Gene Expression and Survival Analyses. Neoplasia (New York, NY). 2017;19(8):649-58.

15. Weinstein JN, Collisson EA, Mills GB, Shaw KR, Ozenberger BA, Ellrott K, et al. The Cancer Genome Atlas Pan-Cancer analysis project. Nature genetics. 2013;45(10):1113-20.

16. Akbani R, Ng PK, Werner HM, Shahmoradgoli M, Zhang F, Ju Z, et al. A pan-cancer proteomic perspective on The Cancer Genome Atlas. Nature communications. 2014;5:3887.

17. Huang da W, Sherman BT, Lempicki RA. Systematic and integrative analysis of large gene lists using DAVID bioinformatics resources. Nature protocols. 2009;4(1):44-57.

18. Warde-Farley D, Donaldson SL, Comes O, Zuberi K, Badrawi R, Chao P, et al. The GeneMANIA prediction server: biological network integration for gene prioritization and predicting gene function. Nucleic acids research. 2010;38(Web Server issue):W214-20.

19. Szklarczyk D, Morris JH, Cook H, Kuhn M, Wyder S, Simonovic M, et al. The STRING database in 2017: quality-controlled protein-protein association networks, made broadly accessible. Nucleic acids research. 2017;45(D1):D362-d8.

20. Su G, Morris JH, Demchak B, Bader GD. Biological network exploration with Cytoscape 3. Current protocols in bioinformatics. 2014;47:8.13.1-24.

21. ten Hoeve J, de Jesus Ibarra-Sanchez M, Fu Y, Zhu W, Tremblay M, David M, et al. Identification of a nuclear Stat1 protein tyrosine phosphatase. Molecular and cellular biology. 2002;22(16):5662-8.

22. Simoncic PD, Lee-Loy A, Barber DL, Tremblay ML, McGlade CJ. The T cell protein tyrosine phosphatase is a negative regulator of janus family kinases 1 and 3 . Current biology : CB. 2002;12(6):446-53.

23. Wiede F, Dudakov JA, Lu KH, Dodd GT, Butt T, Godfrey DI, et al. PTPN2 regulates T cell lineage commitment and alphabeta versus gammadelta specification. The Journal of experimental medicine. 2017;214(9):2733-58.

24. Wiede F, Sacirbegovic F, Leong YA, Yu D, Tiganis T. PTPN2-deficiency exacerbates T follicular helper cell and $B$ cell responses and promotes the development of autoimmunity. Journal of autoimmunity. 2017;76:85-100.

25. LaFleur MW, Nguyen TH, Coxe MA, Miller BC, Yates KB, Gillis JE, et al. PTPN2 regulates the generation of exhausted CD8(+) T cell subpopulations and restrains tumor immunity. Nature immunology. 2019;20(10):1335-47. 
26. PTPN2 Mediates Production of Exhausted T Cells and Antitumor Immunity. Cancer discovery. 2019;9(11):Of5.

27. Wang Z, Shen D, Parsons DW, Bardelli A, Sager J, Szabo S, et al. Mutational analysis of the tyrosine phosphatome in colorectal cancers. Science (New York, NY). 2004;304(5674):1164-6.

28. Gao Q, Zhao YJ, Wang XY, Guo WJ, Gao S, Wei L, et al. Activating mutations in PTPN3 promote cholangiocarcinoma cell proliferation and migration and are associated with tumor recurrence in patients. Gastroenterology. 2014;146(5):1397-407.

29. Slattery ML, Herrick JS, Mullany LE, Samowitz WS, Sevens JR, Sakoda L, et al. The co-regulatory networks of tumor suppressor genes, oncogenes, and miRNAs in colorectal cancer. Genes, chromosomes \& cancer. 2017;56(11):769-87.

30. Zhang Q, Li Y, Zhao R, Wang X, Fan C, Xu Y, et al. The gain-of-function mutation E76K in SHP2 promotes CAC tumorigenesis and induces EMT via the Wnt/beta-catenin signaling pathway. Molecular carcinogenesis. 2018;57(5):619-28.

31. Yu SJ, Yu JK, Ge WT, Hu HG, Yuan Y, Zheng S. SPARCL1, Shp2, MSH2, E-cadherin, p53, ADCY-2 and MAPK are prognosis-related in colorectal cancer. World journal of gastroenterology. 2011;17(15):2028-36.

32. Plani-Lam JH, Chow TC, Fan YH, Garcia-Bloj B, Cheng L, Jin DY, et al. High expression of PTPN21 in B-cell non-Hodgkin's gastric lymphoma, a positive mediator of STAT5 activity. Blood cancer journal. 2016;6:e388.

33. Sun T, Aceto N, Meerbrey KL, Kessler JD, Zhou C, Migliaccio I, et al. Activation of multiple protooncogenic tyrosine kinases in breast cancer via loss of the PTPN12 phosphatase. Cell. 2011;144(5):703-18.

34. Zheng Y, Zhang C, Croucher DR, Soliman MA, St-Denis N, Pasculescu A, et al. Temporal regulation of EGF signalling networks by the scaffold protein Shc1. Nature. 2013;499(7457):166-71.

35. Kodama T, Newberg JY, Kodama M, Rangel R, Yoshihara K, Tien JC, et al. Transposon mutagenesis identifies genes and cellular processes driving epithelial-mesenchymal transition in hepatocellular carcinoma. Proceedings of the National Academy of Sciences of the United States of America. 2016;113(24):E3384-93.

36. Sun $T$, Du W, Xiong H, Yu Y, Weng Y, Ren $L$, et al. TMEFF2 deregulation contributes to gastric carcinogenesis and indicates poor survival outcome. Clinical cancer research : an official journal of the American Association for Cancer Research. 2014;20(17):4689-704.

37. Bamberg A, Redente EF, Groshong SD, Tuder RM, Cool CD, Keith RC, et al. Protein Tyrosine Phosphatase-N13 Promotes Myofibroblast Resistance to Apoptosis in Idiopathic Pulmonary Fibrosis. American journal of respiratory and critical care medicine. 2018;198(7):914-27.

38. Vang T, Liu WH, Delacroix L, Wu S, Vasile S, Dahl R, et al. LYP inhibits T-cell activation when dissociated from CSK. Nature chemical biology. 2012;8(5):437-46.

39. Flego D, Severino A, Trotta F, Previtero M, Ucci S, Zara C, et al. Increased PTPN22 expression and defective CREB activation impair regulatory T-cell differentiation in non-ST-segment elevation acute 
coronary syndromes. Journal of the American College of Cardiology. 2015;65(12):1175-86.

40. Fox JL, Ismail F, Azad A, Ternette N, Leverrier S, Edelmann MJ, et al. Tyrosine dephosphorylation is required for Bak activation in apoptosis. The EMBO journal. 2010;29(22):3853-68.

41. de Voer RM, Hahn MM, Weren RD, Mensenkamp AR, Gilissen C, van Zelst-Stams WA, et al. Identification of Novel Candidate Genes for Early-Onset Colorectal Cancer Susceptibility. PLoS genetics. 2016;12(2):e1005880.

42. Zhang P, Guo A, Possemato A, Wang C, Beard L, Carlin C, et al. Identification and functional characterization of p130Cas as a substrate of protein tyrosine phosphatase nonreceptor 14 . Oncogene. 2013;32(16):2087-95.

43. Cao X, Li Y, Luo RZ, He LR, Yang J, Zeng MS, et al. Tyrosine-protein phosphatase nonreceptor type 12 is a novel prognostic biomarker for esophageal squamous cell carcinoma. The Annals of thoracic surgery. 2012;93(5):1674-80.

44. Cloutier JF, Veillette A. Cooperative inhibition of T-cell antigen receptor signaling by a complex between a kinase and a phosphatase. The Journal of experimental medicine. 1999;189(1):111-21.

45. Wu S, Bottini M, Rickert RC, Mustelin T, Tautz L. In silico screening for PTPN22 inhibitors: active hits from an inactive phosphatase conformation. ChemMedChem. 2009;4(3):440-4.

46. Gjörloff-Wingren A, Saxena M, Williams S, Hammi D, Mustelin T. Characterization of TCR-induced receptor-proximal signaling events negatively regulated by the protein tyrosine phosphatase PEP. Eur J Immunol. 1999;29(12):3845-54.

47. Xia T, Yi XM, Wu X, Shang J, Shu HB. PTPN1/2-mediated dephosphorylation of MITA/STING promotes its 20S proteasomal degradation and attenuates innate antiviral response. Proceedings of the National Academy of Sciences of the United States of America. 2019;116(40):20063-9.

48. Wiede F, Shields BJ, Chew SH, Kyparissoudis K, van Vliet C, Galic S, et al. T cell protein tyrosine phosphatase attenuates $\mathrm{T}$ cell signaling to maintain tolerance in mice. The Journal of clinical investigation. 2011;121(12):4758-74.

49. Francis DM, Różycki B, Koveal D, Hummer G, Page R, Peti W. Structural basis of p38a regulation by hematopoietic tyrosine phosphatase. Nature chemical biology. 2011;7(12):916-24.

50. Muñoz JJ, Tárrega C, Blanco-Aparicio C, Pulido R. Differential interaction of the tyrosine phosphatases PTP-SL, STEP and HePTP with the mitogen-activated protein kinases ERK1/2 and p38alpha is determined by a kinase specificity sequence and influenced by reducing agents. Biochem J. 2003;372(Pt 1):193-201.

51. Francis DM, Kumar GS, Koveal D, Tortajada A, Page R, Peti W. The differential regulation of p38a by the neuronal kinase interaction motif protein tyrosine phosphatases, a detailed molecular study. Structure. 2013;21(9):1612-23.

52. Francis DM, Koveal D, Tortajada A, Page R, Peti W. Interaction of kinase-interaction-motif protein tyrosine phosphatases with the mitogen-activated protein kinase ERK2. PLoS One. 2014;9(3):e91934. 
53. Wang W, Wang J, Li Z, Zhu M, Zhang Z, Wang Y, et al. Promoter hypermethylation of PTPL1, PTPN6, DAPK, p16 and 5-azacitidine inhibits growth in DLBCL. Oncol Rep. 2016;35(1):139-46.

\section{Figures}
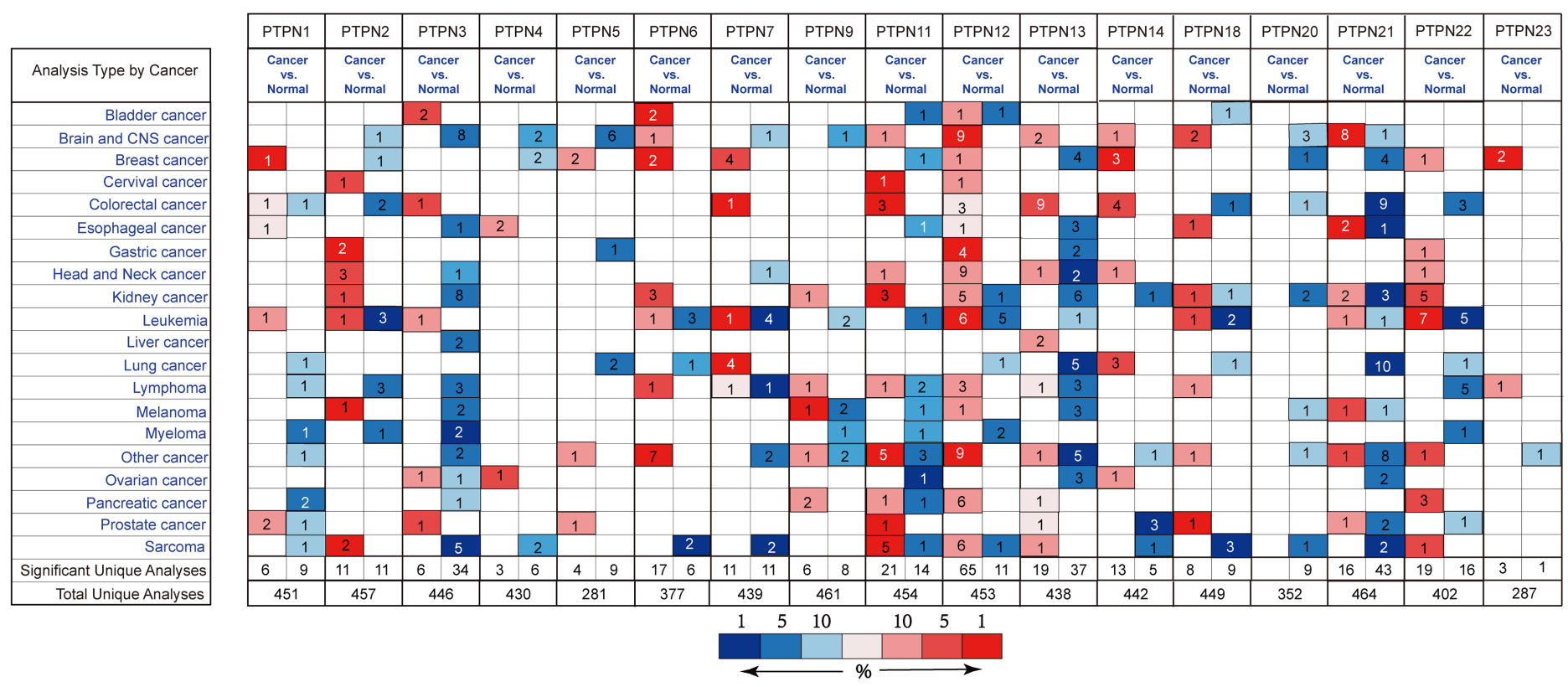

\section{Figure 1}

The expression level of PTPN family genes in different types of cancers. Red and blue stand for the numbers of datasets with statistically significant $(P<0.05)$ increased and decreased levels of PTPN family genes, respectively. 
A

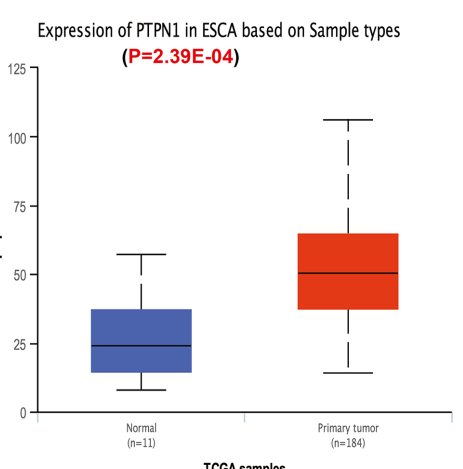

E

Expression of PTPN5 in ESCA based on Sample types

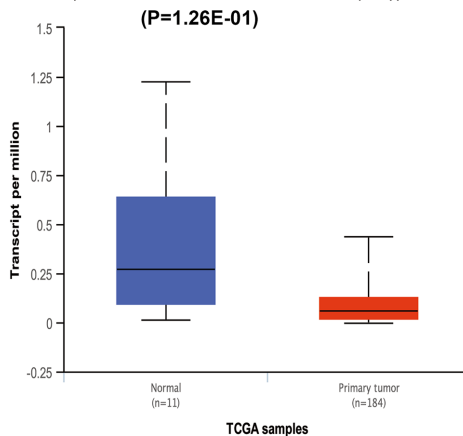

I Expression of PTPN11 in ESCA based on Sample types

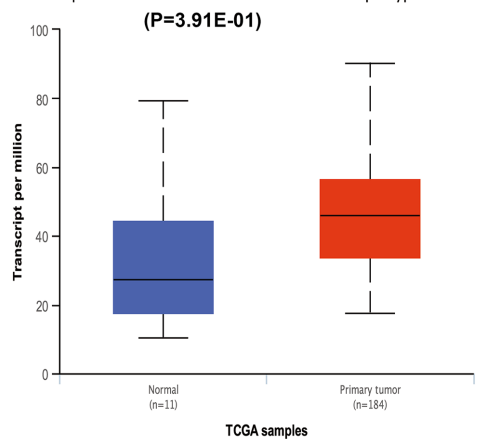

M Expression of PTPN18 in ESCA based on Sample types

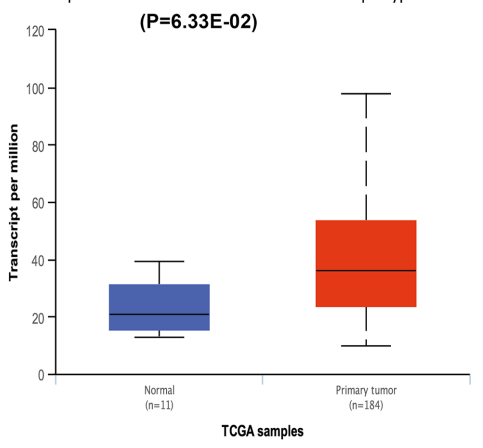

B Expression of PTPN2 in ESCA based on Sample types

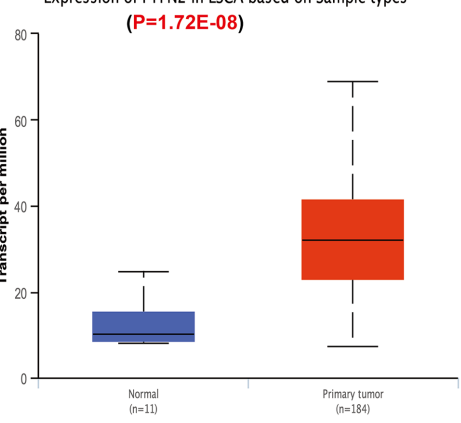

F

Expression of PTPN6 in ESCA based on Sample types

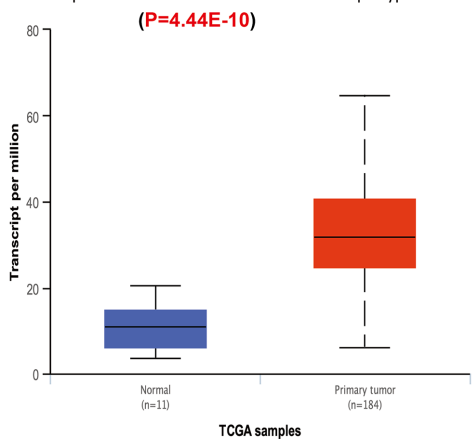

J Expression of PTPN12 in ESCA based on Sample types

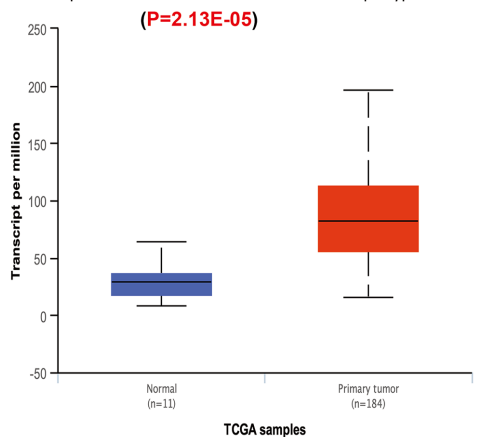

N Expression of PTPN21 in ESCA based on Sample types

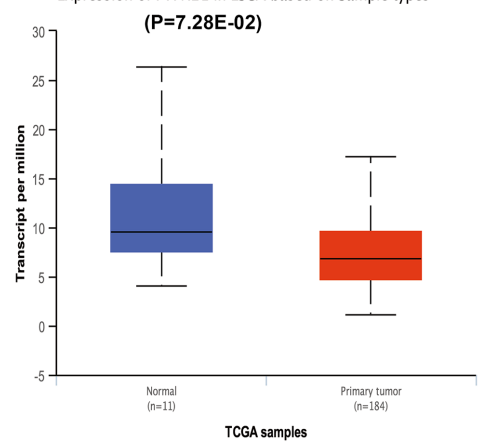

Expression of PTPN3 in ESCA based on Sample types

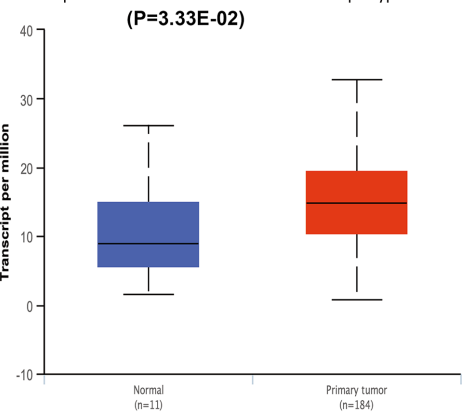

G

Expression of PTPN7 in ESCA based on Sample types

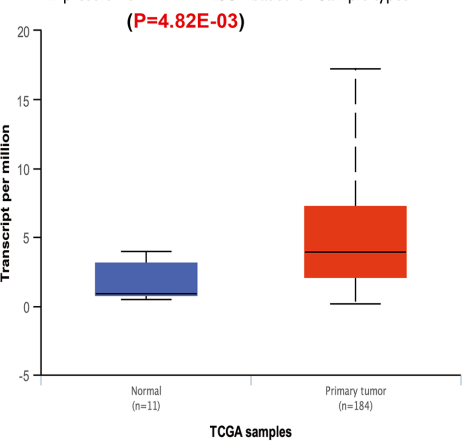

K Expression of PTPN13 in ESCA based on Sample types

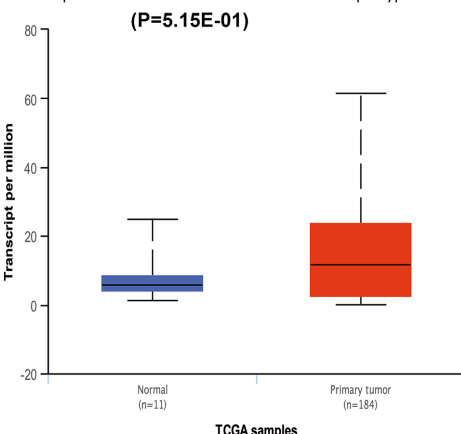

- Expression of PTPN22 in ESCA based on Sample types

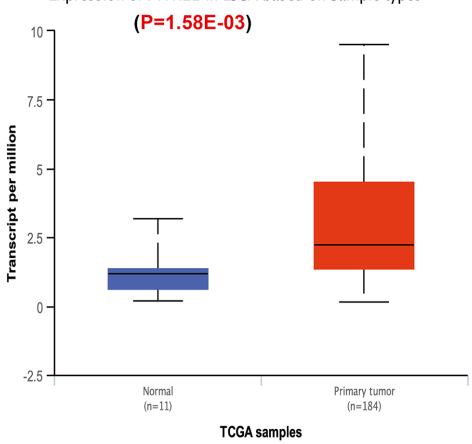

Expression of PTPN4 in ESCA based on Sample types

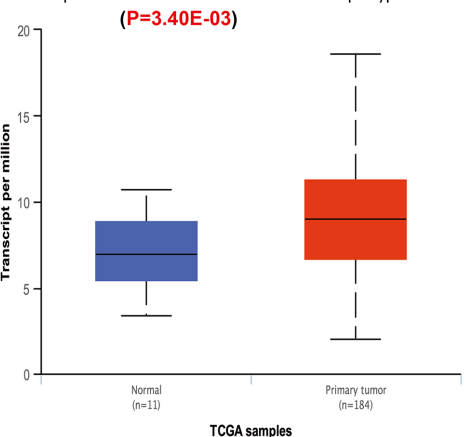

H

Expression of PTPN9 in ESCA based on Sample types

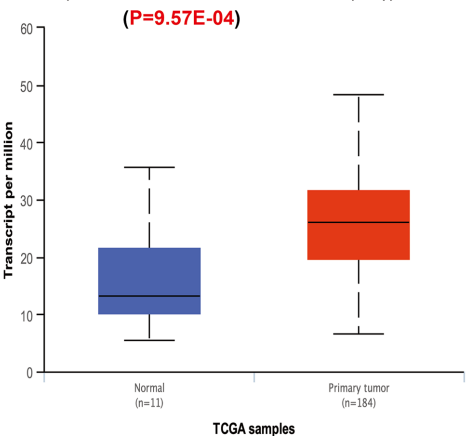

L Expression of PTPN14 in ESCA based on Sample types

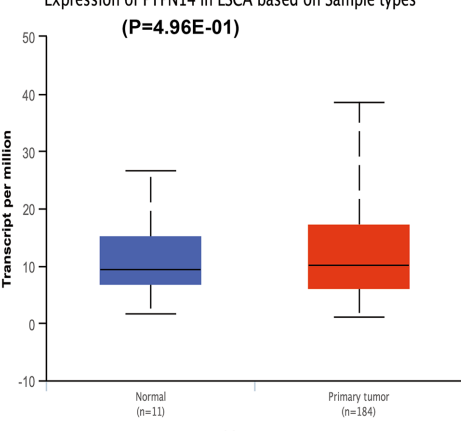

TCGA samples

Expression of PTPN23 in ESCA based on Sample types

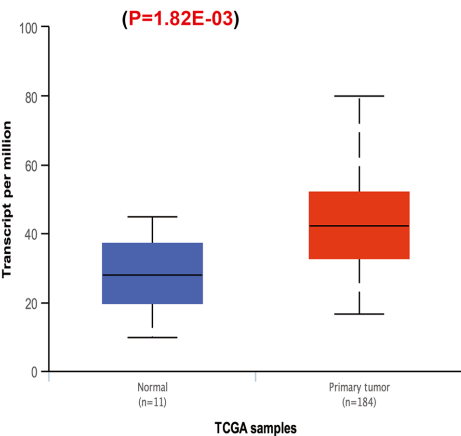

Figure 2

The relative expression of PTPN genes in normal tissues and esophageal carcinoma tissues. (A)PTPN1 (B)PTPN2 (C)PTPN3 (D)PTPN4 (E)PTPN5 (F)PTPN6 (G)PTPN7 (H)PTPN9 (I)PTPN11 (J)PTPN12 (K)PTPN13 (L)PTPN14 (M)PTPN18 (N)PTPN21 (O)PTPN22 (P)PTPN23 
A Expression of PTPN1 in STAD based on Sample types $100-$ $(\mathrm{P}=3.35 \mathrm{E}-14)$

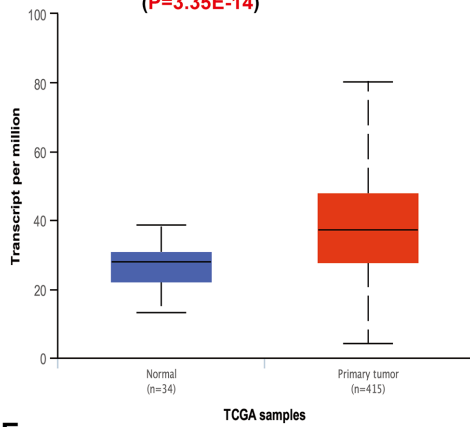

E Expression of PTPN5 in STAD based on Sample types $\left.{ }^{3}\right] \quad(P=9.19 E-02)$

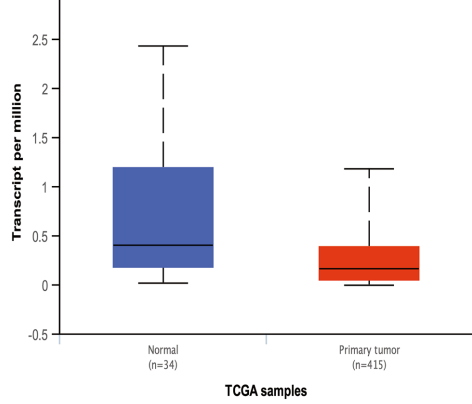

I Expression of PTPN11 in STAD based on Sample types ${ }^{100} 7 \quad(P=8.90 E-07)$

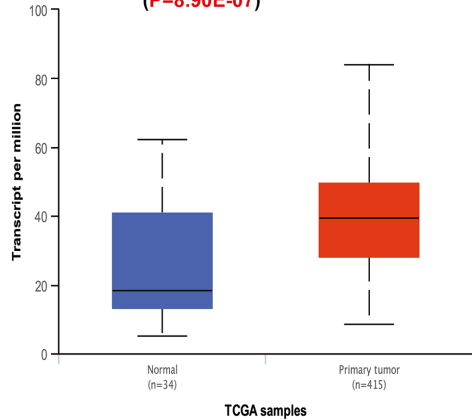

M Expression of PTPN18 in STAD based on Sample types

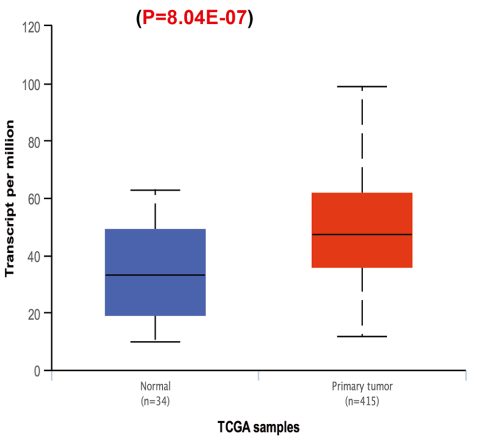

в

Expression of PTPN2 in STAD based on Sample types

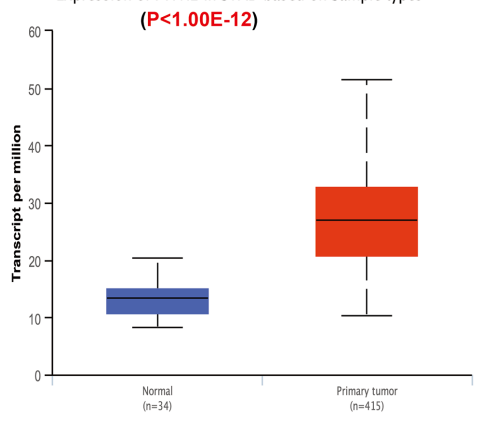

F

Expression of PTPN6 in STAD based on Sample types

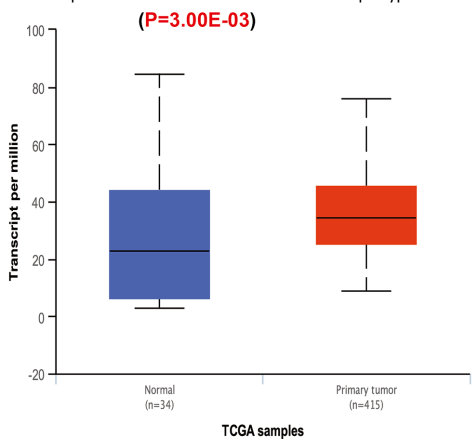

J Expression of PTPN12 in STAD based on Sample types

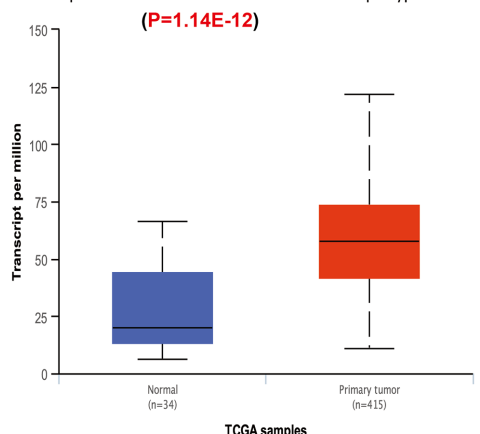

N Expression of PTPN21 in STAD based on Sample types

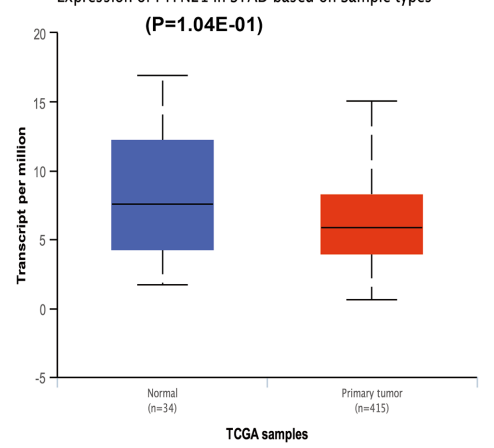

Expression of PTPN3 in STAD based on Sample types ( $P=9.36 \mathrm{E}-07)$

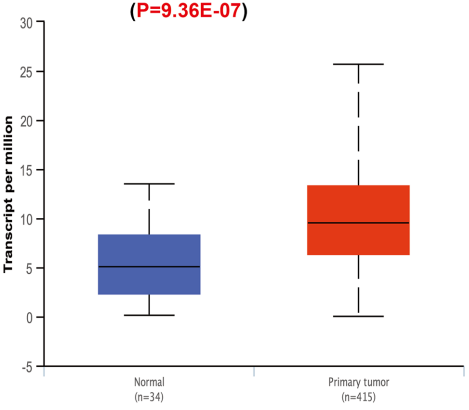

G Expression of PTPN7 in STAD based on Sample types

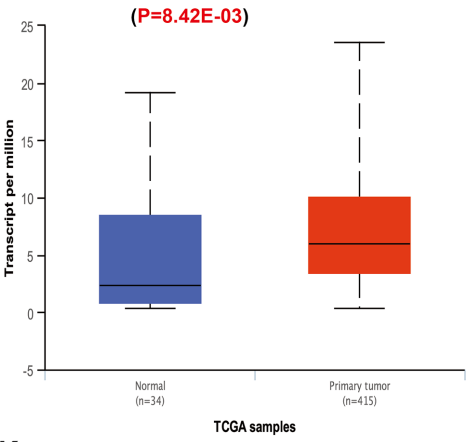

K Expression of PTPN13 in STAD based on Sample types

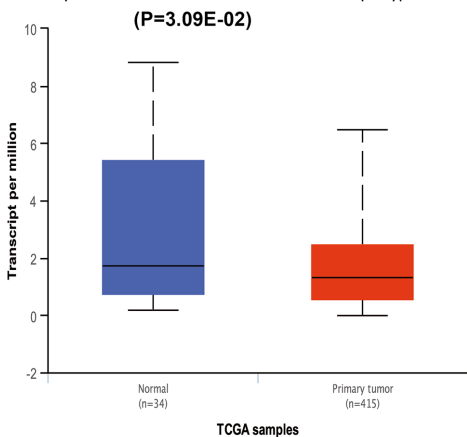

Expression of PTPN22 in STAD based on Sample types

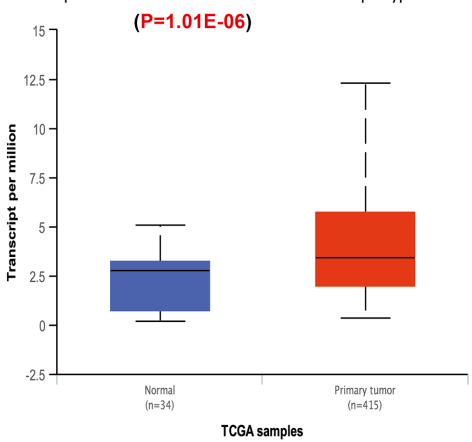

D Expression of PTPN4 in STAD based on Sample types

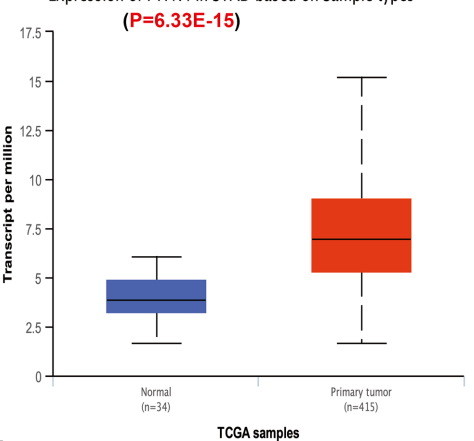

$\mathbf{H}$

Expression of PTPN9 in STAD based on Sample types

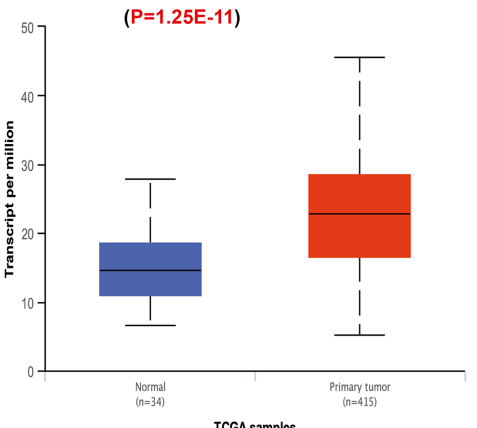

L

Expression of PTPN14 in STAD based on Sample types

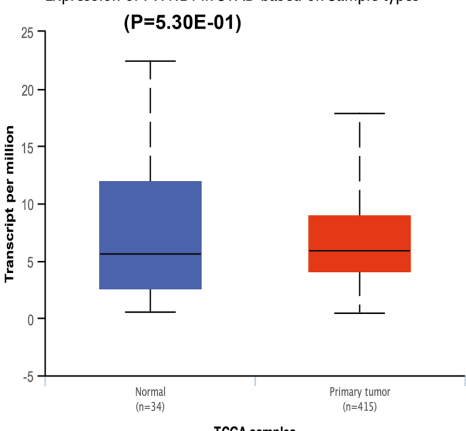

Expression of PTPN23 in STAD based on Sample types

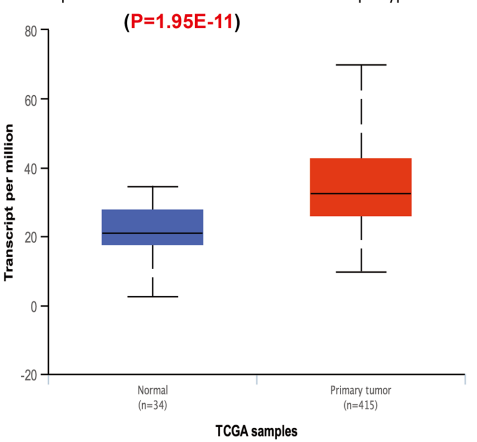

Figure 3

The relative expression of PTPN genes in normal tissues and stomach adenocarcinoma tissues. (A)PTPN1 (B)PTPN2 (C)PTPN3 (D)PTPN4 (E)PTPN5 (F)PTPN6 (G)PTPN7 (H)PTPN9 (I)PTPN11 (J)PTPN12 (K)PTPN13 (L)PTPN14 (M)PTPN18 (N)PTPN21 (O)PTPN22 (P)PTPN23 
A

Expression of PTPN1 in COAD based on Sample types

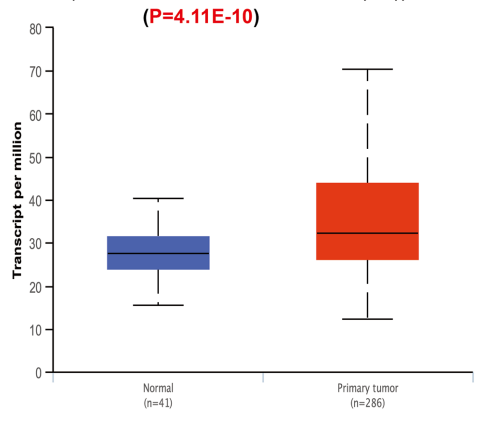

E

Expression of PTPN5 in COAD based on Sample types

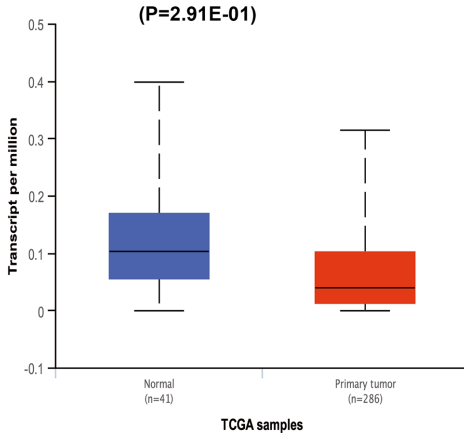

I Expression of PTPN11 in COAD based on Sample types

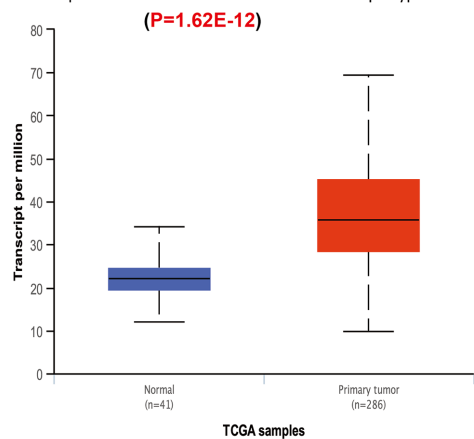

M Expression of PTPN18 in COAD based on Sample types

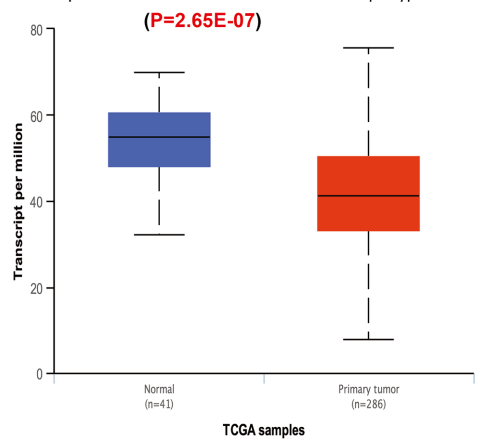

B Expression of PTPN2 in COAD based on Sample types

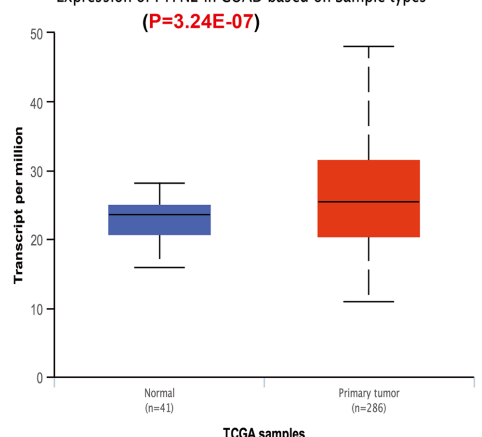

$\mathbf{F}$

Expression of PTPN6 in COAD based on Sample types

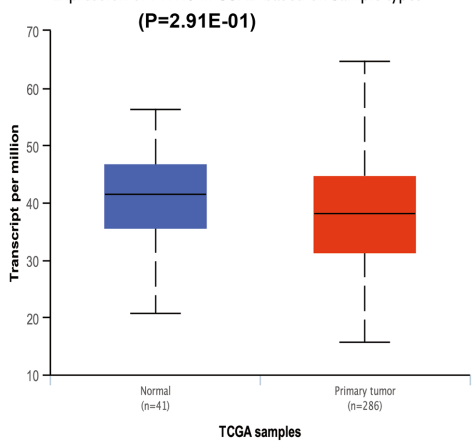

J Expression of PTPN12 in COAD based on Sample types

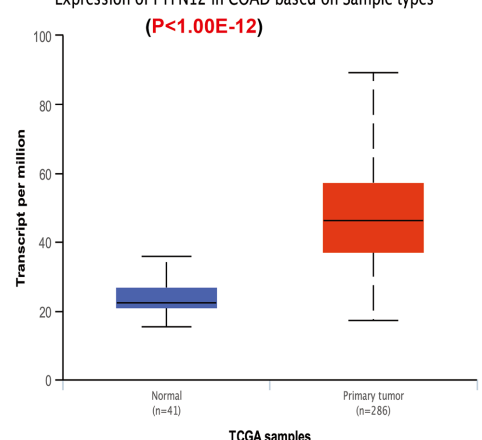

N Expression of PTPN21 in COAD based on Sample types

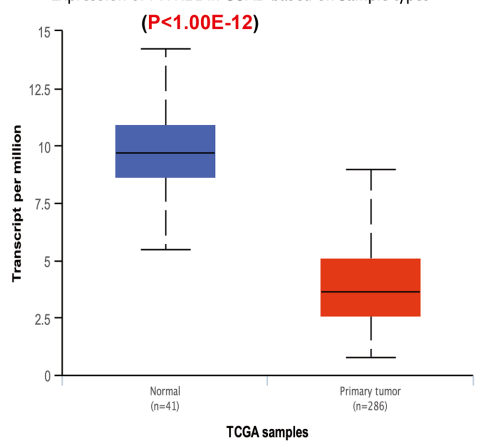

C Expression of PTPN3 in COAD based on Sample types (P=1.34E-02)

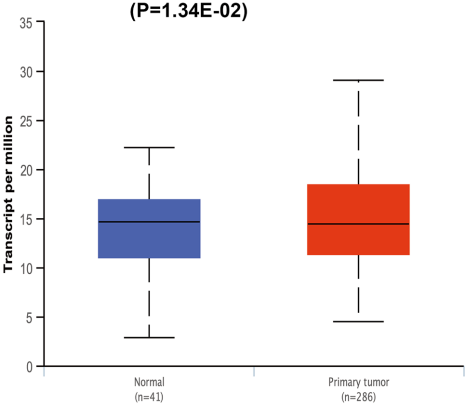

G Expression of PTPN7 in COAD based on Sample types

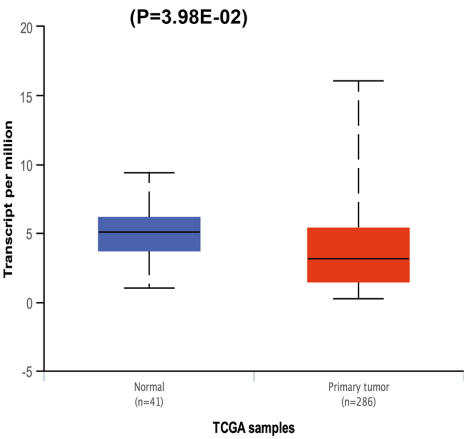

K Expression of PTPN13 in COAD based on Sample types

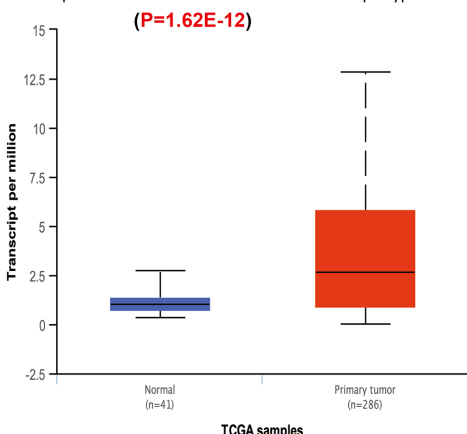

Expression of PTPN22 in COAD based on Sample types

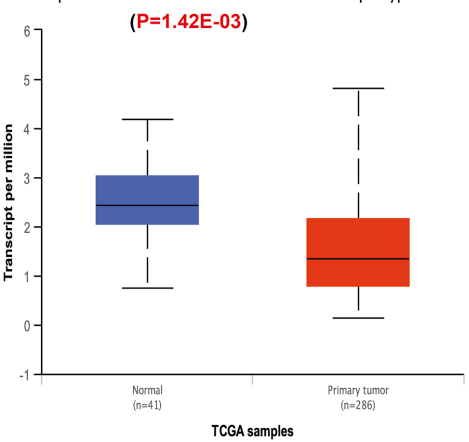

Expression of PTPN4 in COAD based on Sample types

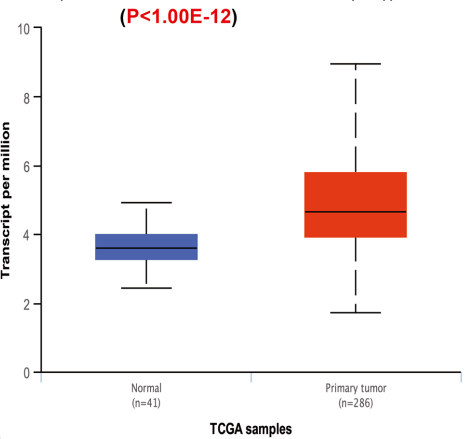

H

Expression of PTPN9 in COAD based on Sample types
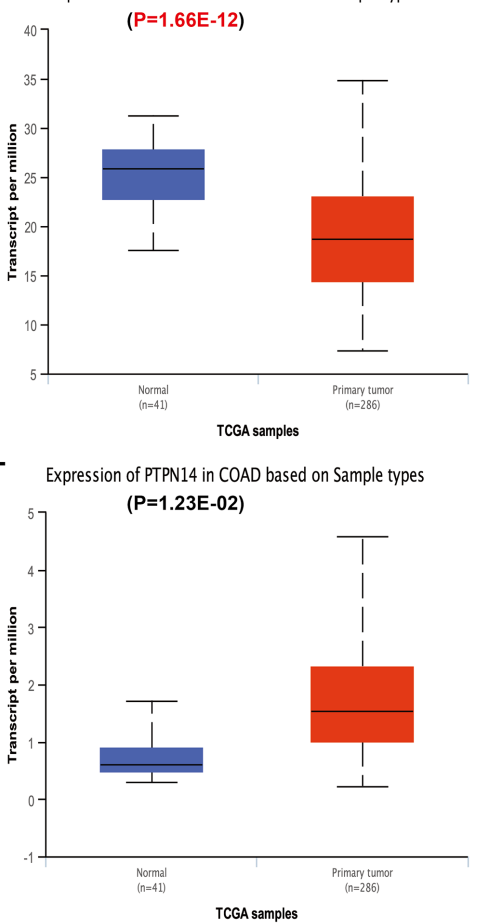

Expression of PTPN23 in COAD based on Sample types

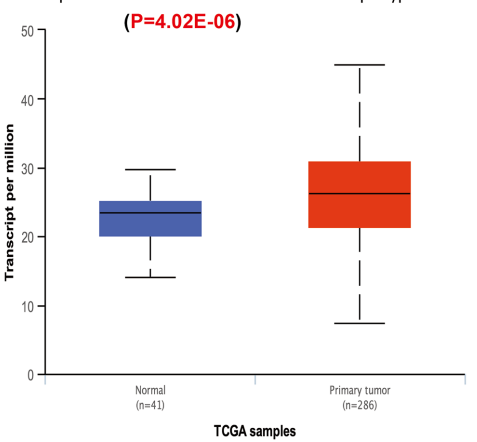

Figure 4

The relative expression of PTPN genes in normal tissues and colon adenocarcinoma tissues. (A)PTPN1 (B)PTPN2 (C)PTPN3 (D)PTPN4 (E)PTPN5 (F)PTPN6 (G)PTPN7 (H)PTPN9 (I)PTPN11 (J)PTPN12 (K)PTPN13 (L)PTPN14 (M)PTPN18 (N)PTPN21 (0)PTPN22 (P)PTPN23 
A

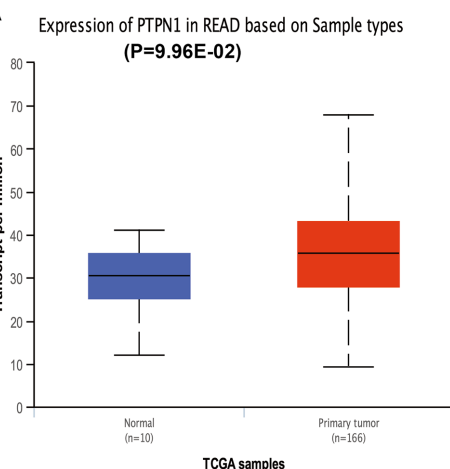

E Expression of PTPN5 in READ based on Sample types

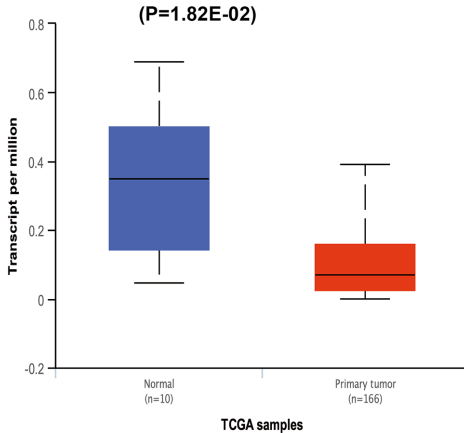

I Expression of PTPN11 in READ based on Sample types

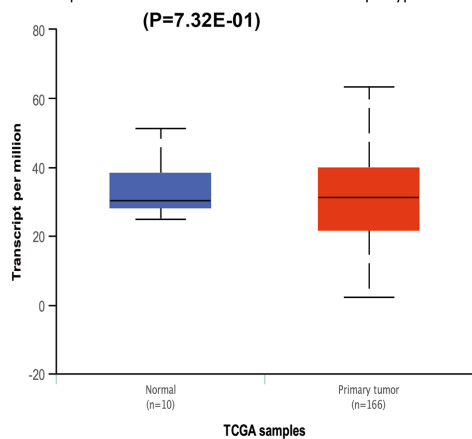

M Expression of PTPN18 in READ based on Sample types

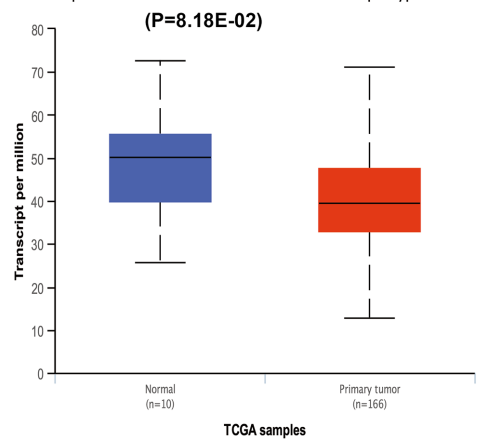

B Expression of PTPN2 in READ based on Sample types

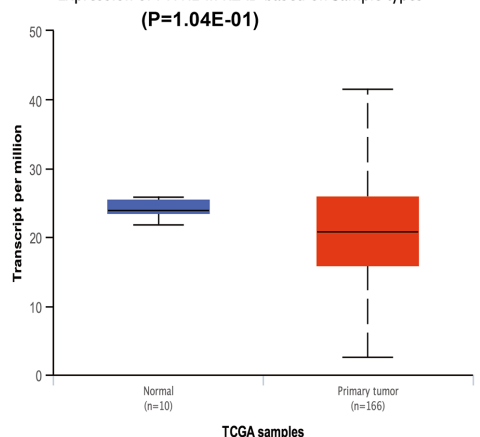

$\mathbf{F}$

Expression of PTPN6 in READ based on Sample types

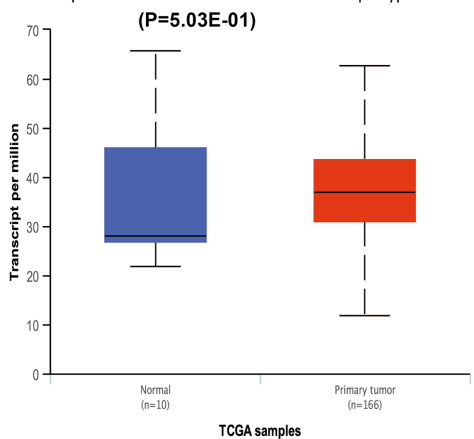

J Expression of PTPN12 in READ based on Sample types

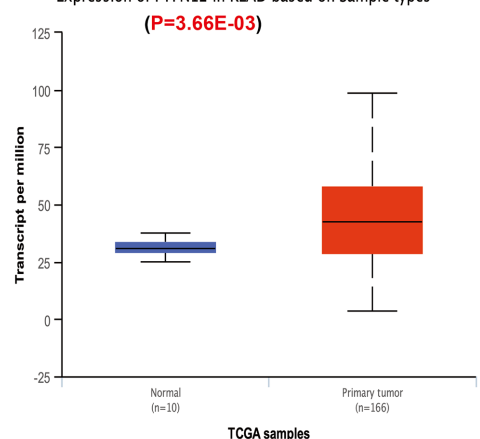

N Expression of PTPN21 in READ based on Sample types

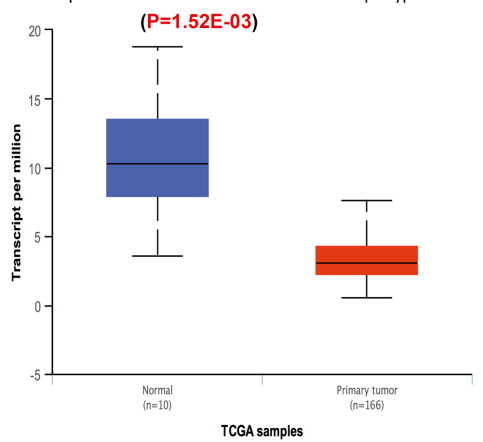

Cxpression of PTPN3 in READ based on Sample types

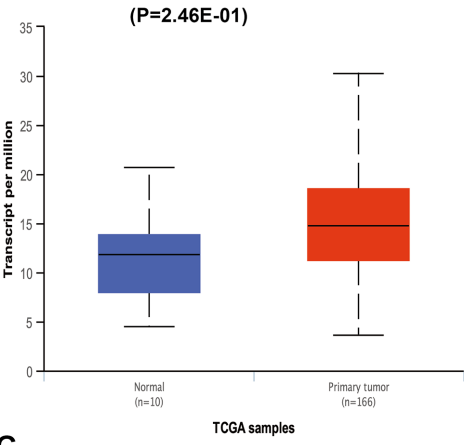

G

Expression of PTPN7 in READ based on Sample types

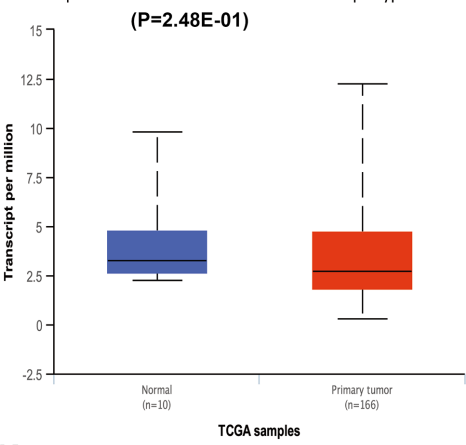

K Expression of PTPN13 in READ based on Sample types

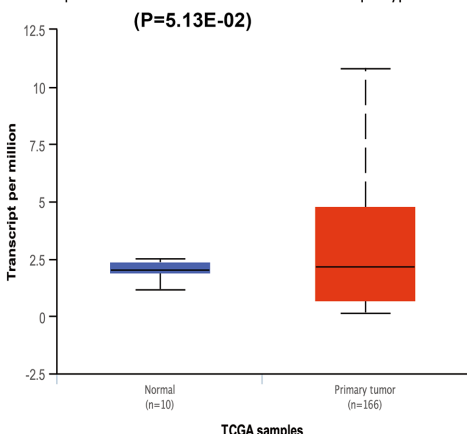

Expression of PTPN22 in READ based on Sample types

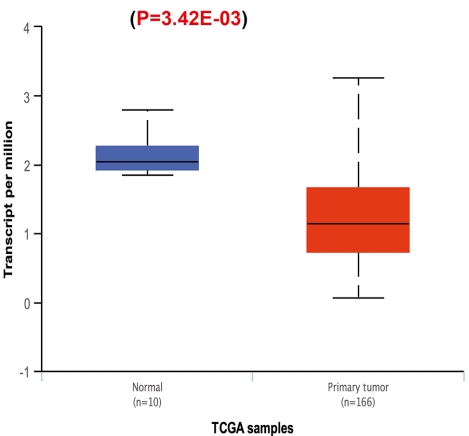

Expression of PTPN4 in READ based on Sample types

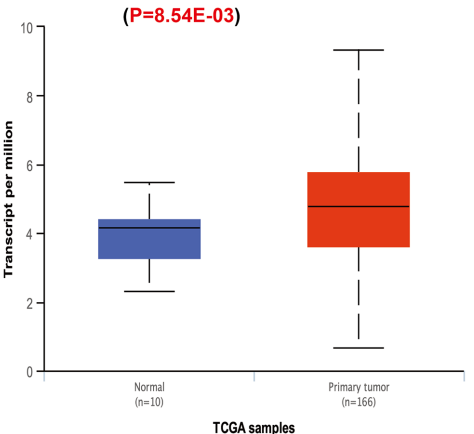

H

Expression of PTPN9 in READ based on Sample types

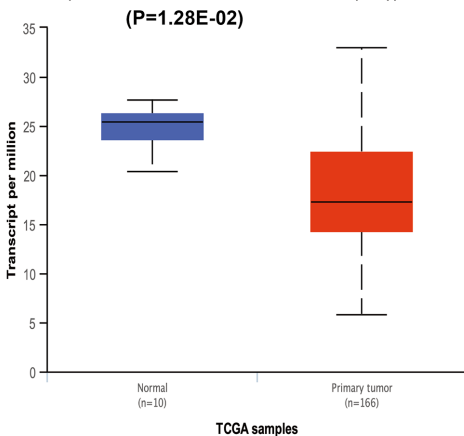

L Expression of PTPN14 in READ based on Sample types

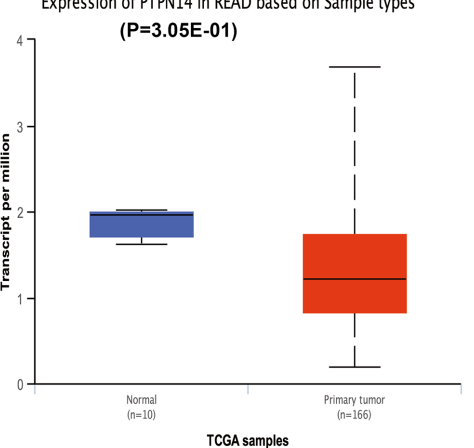

Expression of PTPN23 in READ based on Sample types

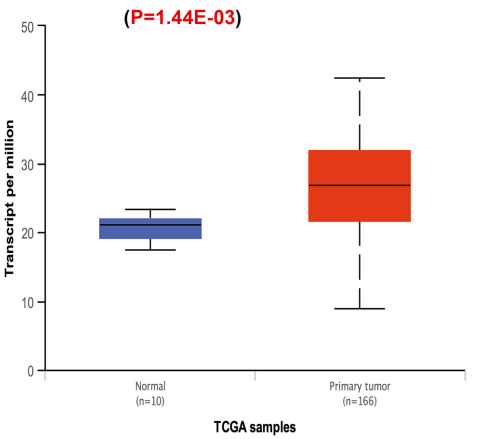

Figure 5

The relative expression of PTPN genes in normal tissues and rectum adenocarcinoma tissues. (A)PTPN1 (B)PTPN2 (C)PTPN3 (D)PTPN4 (E)PTPN5 (F)PTPN6 (G)PTPN7 (H)PTPN9 (I)PTPN11 (J)PTPN12 (K)PTPN13 (L)PTPN14 (M)PTPN18 (N)PTPN21 (O)PTPN22 (P)PTPN23 
a

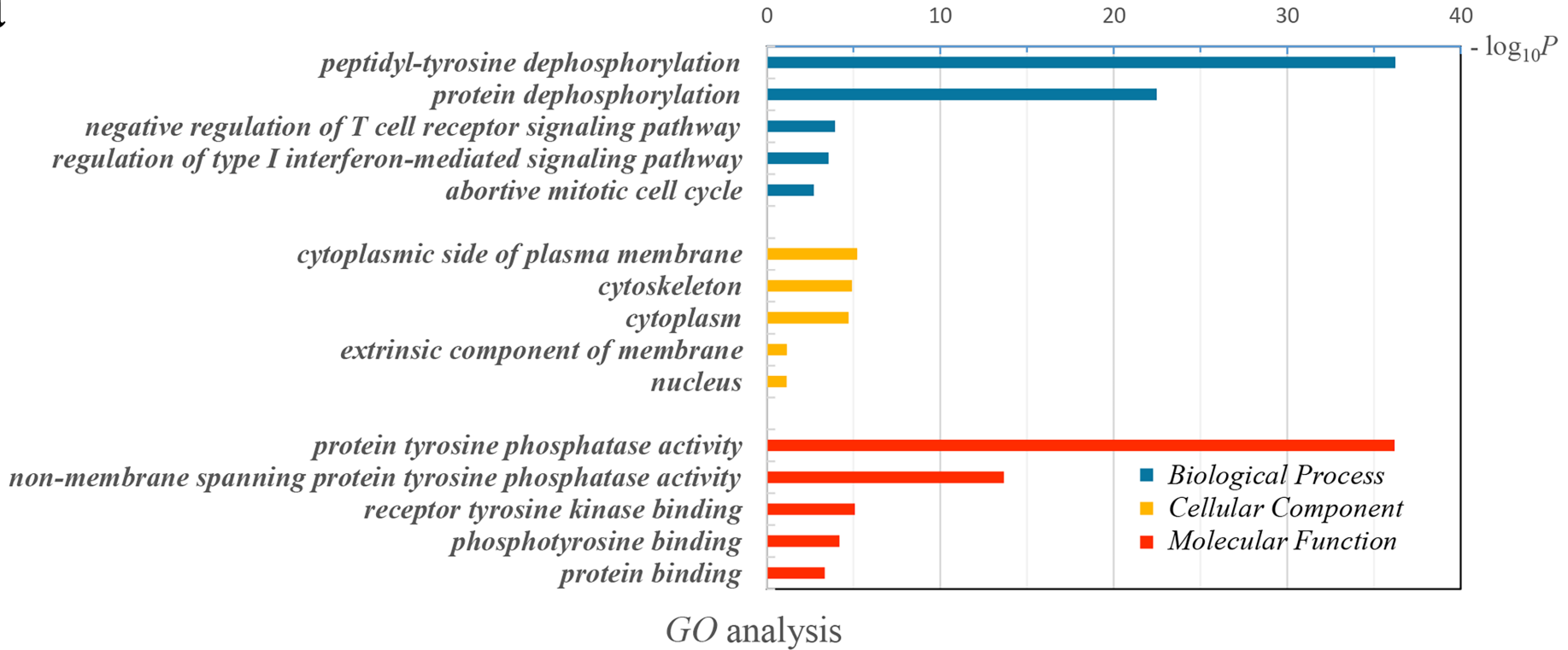

b
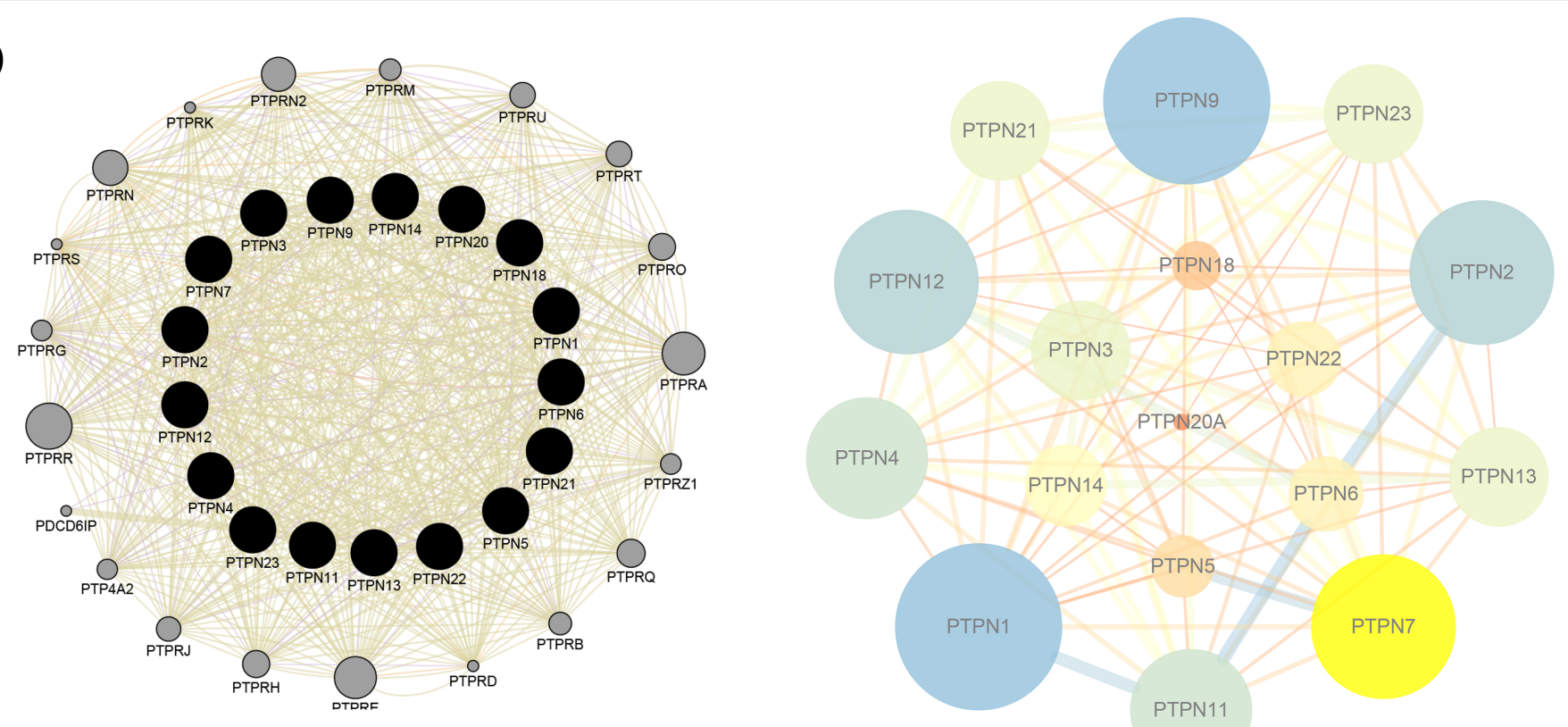

Networks

Functions

- Shared protein domains

$\mathrm{N} / \mathrm{A}$

- Co-expression

- Consolidated-Pathways-2013

- Physical Interactions

\section{Figure 6}

Enrichment and correlation analysis among PTPN family genes. a GO analysis of PTPN family genes. The top 5 enriched categories for Biological Process, Cellular Component, and Molecular Function were showed. b Gene-gene interaction network among PTPN gene family members. c Protein-protein interaction network among PTPN gene family members.

\section{Supplementary Files}


This is a list of supplementary files associated with this preprint. Click to download.

- Additionalfile1.xlsx 